\title{
MAKING THE BUSINESS CASE FOR PROCESS SAFETY USING VALUE-AT-RISK CONCEPTS
}

\author{
A Thesis \\ by \\ JAYMING SHA FANG \\ Submitted to the Office of Graduate Studies of \\ Texas A\&M University \\ in partial fulfillment of the requirements for the degree of \\ MASTER OF SCIENCE
}

August 2006

Major Subject: Chemical Engineering 


\title{
MAKING THE BUSINESS CASE FOR PROCESS SAFETY USING VALUE-AT-RISK CONCEPTS
}

\author{
A Thesis \\ by \\ JAYMING SHA FANG \\ Submitted to the Office of Graduate Studies of \\ Texas A\&M University \\ in partial fulfillment of the requirements for the degree of \\ MASTER OF SCIENCE
}

\begin{abstract}
Approved by:
Chair of Committee, David M. Ford

Committee members, M. Sam Mannan

Daren Cline

Head of Department, Kenneth Hall
\end{abstract}

August 2006

Major Subject: Chemical Engineering 


\begin{abstract}
Making the Business Case for Process Safety Using Value-at-Risk

Concepts. (August 2006)

Jayming Sha Fang, B.S., The University of Texas at Austin

Chair of Advisory Committee: Dr. David M. Ford
\end{abstract}

An increasing emphasis on chemical process safety over the last two decades has led to the development and application of powerful risk assessment tools. Hazard analysis and risk evaluation techniques have developed to the point where quantitatively meaningful risks can be calculated for processes and plants. However, the results are typically presented in semi-quantitative "ranked list" or "categorical matrix" formats, which are certainly useful but not optimal for making business decisions. A relatively new technique for performing valuation under uncertainty, Value at Risk (VaR), has been developed in the financial world. VaR is a method of evaluating the probability of a gain or loss by a complex venture, by examining the stochastic behavior of its components. We believe that combining quantitative risk assessment techniques with VaR concepts will bridge the gap between engineers and scientists who determine process risk and business leaders and policy makers who evaluate, manage, or regulate risk. We present a few basic examples of the application of VaR to hazard analysis in the chemical process industry. We discover that by using the $\mathrm{VaR}$ tool we are able to present data that allows management to make better informed decisions. 
My late uncle

\section{Charlie Sha}




\section{ACKNOWLEDGEMENTS}

There are so many people I want to think during my three-and-a-half years here at A\&M. I would like to thank my advisor, David M. Ford, for his help and guidance, not only professionally but personally as well. I would also like to thank Daren Cline and M. Sam Mannan for being part of the committee and for their help.

I would like to thank my group members who are also my friends in both Ford and Mannan’s group. I would like to thank Michael O’Connor who founded the Mary O’Connor Process Safety Center. I am grateful to Mary Cass and Towanna Hubacek for making the paperwork easier.

Last but not least, I want to thank all the members at Fellowship Church, including Pastor Ray Muenich, for all his help and guidance. 


\section{TABLE OF CONTENTS}

\section{Page}

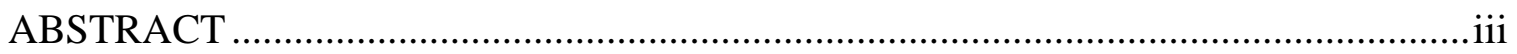

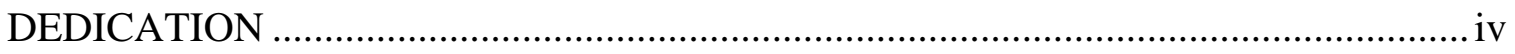

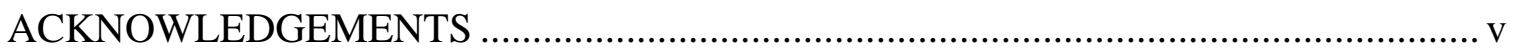

TABLE OF CONTENTS ..................................................................................... vi

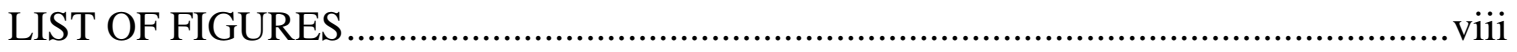

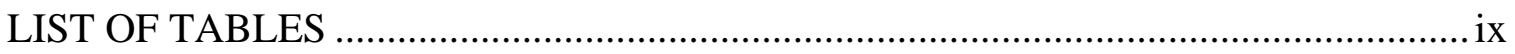

CHAPTER

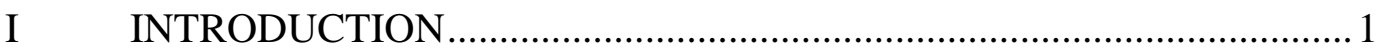

1.1 Background ..................................................................... 1

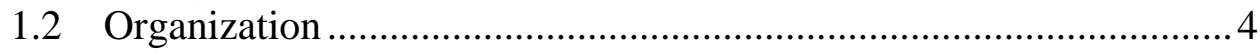

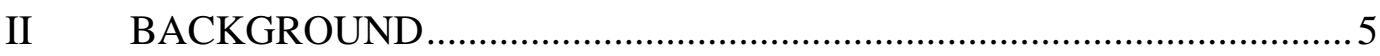

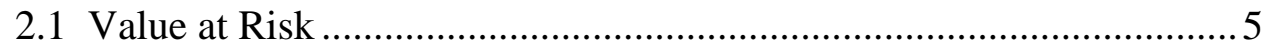

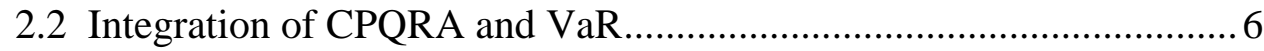

III APPLICATION EXAMPLES......................................................... 8

3.1 First Example Problem: Leak from LPG Storage Tank ..................... 8

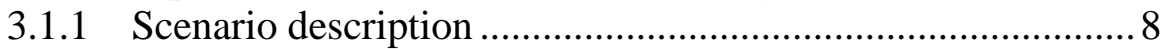

3.1.2 Point system for event damage.......................................... 10

3.1.3 VaR for the case of no uncertainty in event damage.............11

3.1.4 VaR for the case of uniform uncertainty in event damage... 14

3.1.5 VaR for the case of Gaussian uncertainty in event damage.17

3.1.6 VaR for the case of beta uncertainty in event damage ..........18

3.2 Second Example Problem: Loading of Chlorine Rail Tank Car ........ 20

3.2.1 Scenario description ....................................................... 20

3.2.2 Point scale for damage events ......................................... 21

3.2.3 Analysis of scenario ........................................................ 23 
CHAPTER $\quad$ Page

IV LAYERS OF PROTECTION ANALYSIS EXAMPLE.......................... 25

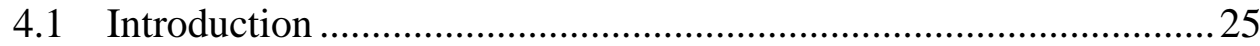

4.1.1 Process description and potential failures ......................... 25

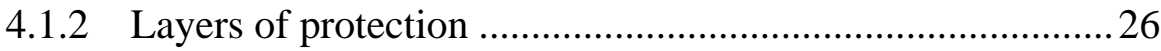

4.2 Theory and Methods.................................................................. 30

4.2.1 Calculations of frequencies and cost values........................ 30

4.2.2 Generation of frequency-cost graphs and VaR statistics .....32

4.2.3 Total expected cost value ..................................................... 34

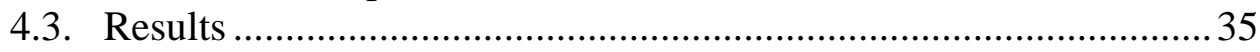

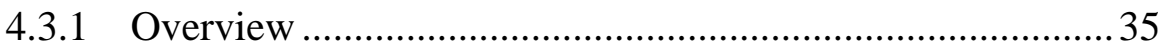

4.3.2 Base case .................................................................... 42

4.3.3 Case without overspeed interlock 1 ...................................43

4.3.4 Case without overspeed interlock 2 .................................. 43

4.3.5 Case without the vibrational interlock ................................. 44

4.3.6 Total expected value for damage cost ............................... 44

4.3.7 Best choice among the four scenarios? ............................... 45

V CONCLUSIONS AND FUTURE WORK ........................................ 47

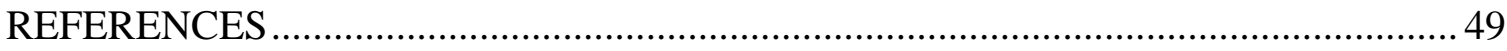

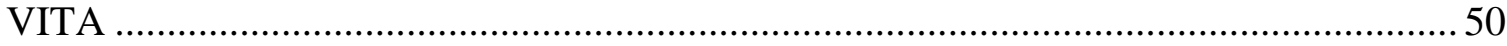




\section{LIST OF FIGURES}

Page

Figure 1. Flow chart of the integration of VaR and CPQRA .................................... 7

Figure 2. Damage outcome frequencies for the LPG leak (no uncertainty)................ 12

Figure 3. Cumulative mass function for the LPG leak (no uncertainty)..................... 13

Figure 4. Frequency density function for the LPG leak (uniform uncertainty)........... 15

Figure 5. Cumulative distribution function for the LPG leak (uniform uncertainty) .. 16

Figure 6. Outcome density function for the LPG leak (Gaussian uncertainty) ........... 17

Figure 7. Cumulative distribution function for the LPG leak(Gaussian uncertainty) . 18

Figure 8. Frequency density function for the LPG leak (beta uncertainty) ................. 19

Figure 9. Cumulative distribution function for the LPG leak (beta uncertainty) ........ 20

Figure 10. Frequency mass function for the chlorine rail car problem........................ 23

Figure 11. Cumulative distribution function for the chlorine rail car problem ............. 24

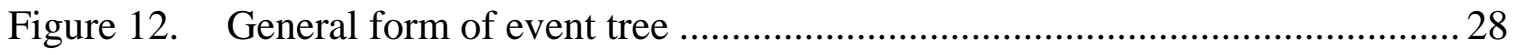

Figure 13a. Outcome frequencies at all cost levels across all scenarios ........................ 36

Figure 13b. Close-up view of outcome frequencies at the $\$ 2,500,000$ cost level .......... 37

Figure 13c. Close-up view of outcome frequencies at the $\$ 7,100,000$ cost level ........... 38

Figure 14a. Cumulative mass probability functions for each scenario.......................... 39

Figure 14b. Close-up view of the cumulative mass functions at the $\$ 2,500,000$ cost..... 40

Figure 14c. Close-up view of the cumulative mass functions at the $\$ 7,100,000$ cost..... 41

Figure 15. Total expected cost values for the four scenarios ................................... 45 


\section{LIST OF TABLES}

Page

Table 1. Data for the LPG leak problem .................................................................. 9

Table 2. Revised data for the LPG leak problem ..................................................... 11

Table 3. Data for the chlorine rail car problem .......................................................... 21

Table 4. Frequencies and cost data for all the events and cases................................... 29

Table 5. Frequency and cumulative probability data for all of the scenarios .................. 42 


\section{CHAPTER I}

\section{INTRODUCTION}

\subsection{Background}

Due to the inherent sensitivity of the chemical process industry (CPI) to the consequences of failure, chemical process safety has been a major concern for some time (AICHE, 1989). In the current era of market mechanisms and efficiency, the underlying driving force is to make production as cheap as possible, to save investment money where possible, and to avoid overdoing measures that just serve to safeguard. History, however, reveals that safety does pay in the long run. (Pasman, 2000) Chemical process quantitative risk assessment (CPQRA) identifies areas in operations, engineering, and management systems that might be modified to reduce process risk. CPQRA deals with both aspects of risk, namely likelihood and consequence. Likelihood is typically estimated through some combination of historical data and fault/event tree analysis. Consequence modeling generally consists of two parts; detailed science models predict the parameters of incident-specific events (e.g. gas release, explosion overpressure), and effect/mitigation models predict the final consequences on people and the environment (natural and built). The product of likelihood and consequence is a measure of risk.

This thesis conforms to the Journal of Loss Prevention in the Process Industries. 
Presently, CPQRA has developed to the point where quantitatively meaningful risks may be calculated for individual processes and entire plants. (Fang et al., 2004) ${ }^{1}$

Obviously, implementing safety devices and procedures to remove all risks in a chemical plant is not feasible. Thus, an important part of a CPQRA analysis is prioritizing the risks for appropriate action. The results are typically reported in a likelihood-consequence matrix format, or perhaps in a ranked list. While this semiquantitative approach is useful, we believe that CPQRA has progressed to a point where the results may be presented in more detail and with more quantitative precision. Furthermore, they should be presented in a comprehensive format that is useful to CPI management and other policy makers. This is not an easy task, primarily due to the inherently probabilistic nature of the problem. However, the rewards of such an approach would be substantial; a more quantitative and coherent business case for process safety would certainly result in a better-focused investment by the CPI. (Fang et al., 2004)

In this thesis, we present a new approach for understanding, organizing, and packaging the results of CPQRA analyses. The approach is based on a technique, Value at Risk (VaR), borrowed from the financial industry (Jorion, 2001); it will provide a bridge between the engineers and scientists who calculate process risk and the business leaders and policy makers who evaluate, manage, or regulate risk in a broader context. VaR is a method of evaluating the probability of a gain or loss by a complex venture, by

\footnotetext{
${ }^{1}$ Reprinted with permission from "Making the business case for process safety using value-at-risk concepts” Fang, J.S., Ford, D.F., \& Mannan, M.S, 2004. Journal of Hazardous Materials, 115, 17-26. 2004 by Elsevier.
} 
examining the stochastic behavior of its components. The framework is firmly grounded in the theory of $\mathrm{VaR}$, yet flexible enough so that it may be:

- $\quad$ used at several different organizational levels (process, plant, industry segment).

- $\quad$ integrated with other business risk concerns (operational, market) so that complete and accurate cost-benefit decisions may be made.

- $\quad$ implemented in software targeted for industrial risk professionals.

- $\quad$ extended to other types of risk (environmental, societal) and for use by other stakeholders (governmental agencies, public interest groups).

(Fang et al., 2000)

The primary focus of this thesis is to introduce the approach and demonstrate its use on case problems from the literature. We note that VaR concepts have begun to appear in other areas of process design research. For example, Barbaro and Bagajewicz (in press) have employed VaR in developing a two-stage stochastic formulation for managing financial risk in planning under uncertainty.

In addition to the CPQRA analyses, we investigate the Layers of Protection Analysis (LOPA) to VaR analysis. LOPA defines a series of independent layers of defense against harmful events and their consequences. This represents an increase in complexity because this allows us to investigate the impact of individual safety devices (i.e. interlocks, alarms) on the inherent safety of the component and how removing or placing a safety device can affect the safety. However, as before, the VaR is still represented as one curve. (Fang et al., 2004) 


\subsection{Organization}

Chapter II contains the theoretical development for combining VaR and CPQRA. Chapter III demonstrates the procedure on two different example problems using the basic concepts. Chapter IV demonstrates a more advanced case study using dollars and process known as the Layers of Protection Analysis technique. The first example is based on a single event tree and a simple damage valuation index, with various layers of probabilistic complexity sequentially added in. The second is closer to a real-world example, using a hazard quantification index from the literature. And the third is the closest to simulating a real world problem that uses valuation in terms of dollars and uses several event trees, consisting of independent layers of protection. Chapter V concludes this study. 


\section{CHAPTER II}

\section{BACKGROUND}

\subsection{Value at Risk}

VaR is a method of evaluating the probability of a gain or loss by a complex financial venture, by examining the stochastic behavior of its components (Jorion, 2001). VaR approaches generally involve a combination of likelihood estimation and valuation: how likely is an event to happen, and what is the financial impact on the portfolio? Quantification of both of these aspects may involve sophisticated probabilistic analyses. A major strength of the $\mathrm{VaR}$ technique is that it provides a total cost-benefit analysis of an entire portfolio in terms of a single probability distribution function for value. VaR itself is technically defined as the worst loss that is expected in a portfolio, within a given probability, over a specified time period. (Fang et al., 2004)

The flexibility of the VaR approach (i.e., the ability to accept input from different events), combined with the comprehensive, straightforward presentation of results (i.e., the use of a single probabilistic value function), makes it attractive for application to problems in CPQRA. 


\subsection{Integration of CPQRA and VaR}

The diagram in Figure 1 shows how we envision the procedure. Traditional CPQRA tools are used to determine the probabilities and consequences of undesired events associated with a plant or process. The consequences are passed to a valuation model, where they are assigned values (or distributions of values). The valuation may be done in monetary terms, or with a customized index appropriate to the particular situation or stakeholders. For undesired events, the values will typically be negative by convention. The results of the CPQRA and valuation are sent to the VaR engine, where they are combined to generate a single $\mathrm{VaR}$ probability distribution function representing process/plant value. (Fang et al., 2004)

The VaR approach is capable of handling complex situations in which the fundamental stochastic events are related in a nonlinear fashion within the portfolio; this level of complexity typically requires simulation using Monte Carlo techniques (Jorion, 2001) This level of treatment is not required for the simple example situations described below, but it might be for many real-world problems in the CPI.

We also note that the cumulative versions of our VaR probability curves are somewhat analogous to the frequency-number, or F-N, curves often used to describe societal risk (AICHE, 1989). F-N curves show the cumulative frequency of undesired events with respect to the number of individuals affected (e.g. killed, injured, exposed). Our cumulative VaR curves represent the cumulative frequency of experiencing a loss with respect to the damage value. In this thesis, we consider damage value in an abstract sense and do not relate it to human life. 


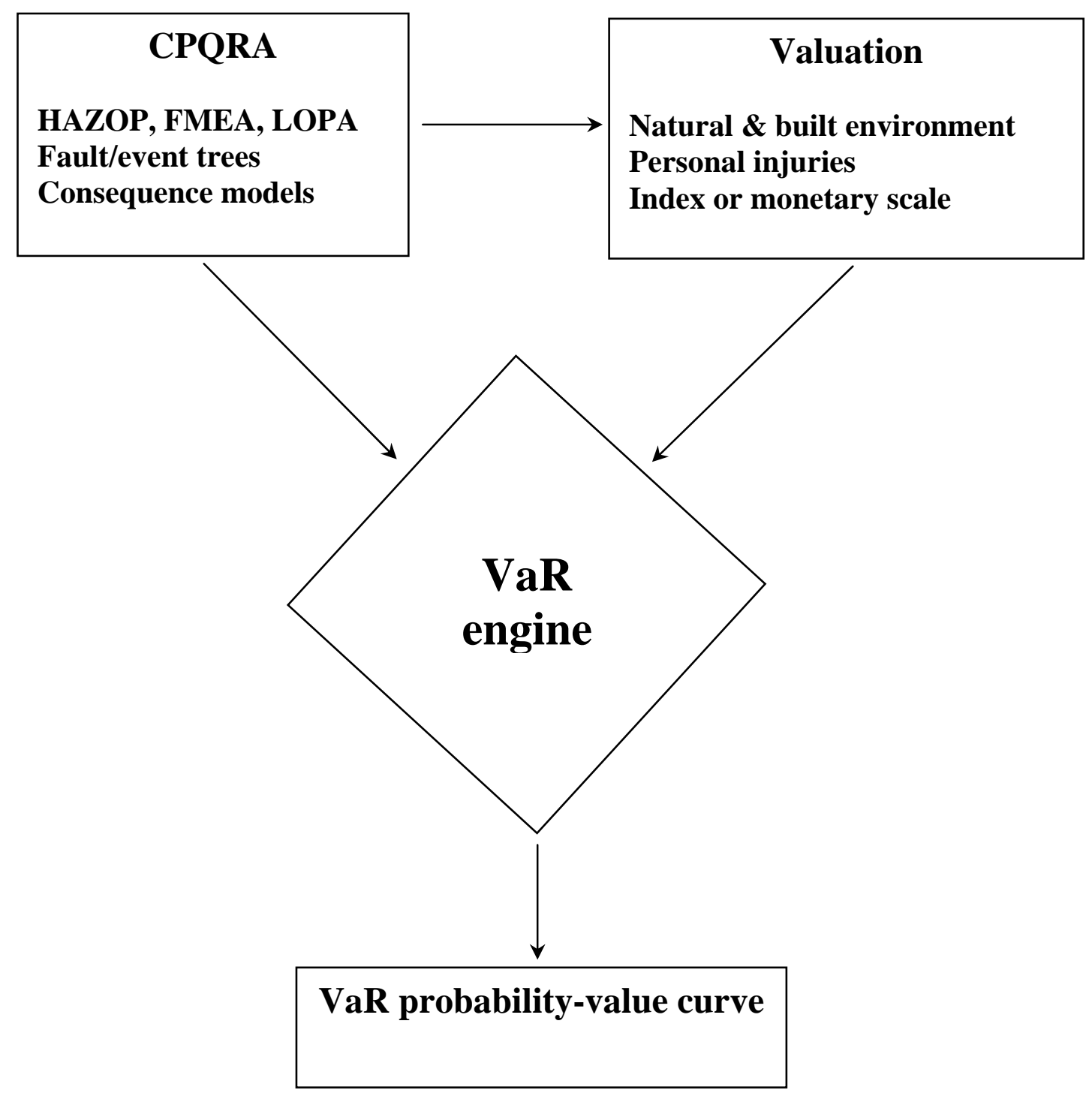

Figure 1. Flow chart of the integration of VaR and CPQRA 


\section{CHAPTER III}

\section{APPLICATION EXAMPLES}

\subsection{First Example Problem: Leak from LPG Storage Tank}

This example problem applies a VaR analysis to a problem illustrated in Chapter 3 of the CPQRA. The possible events and outcomes, and their frequencies, are taken directly from that example. We created the damage index described below, specifically for illustrative purposes related to this example. The values of the damage index for the different possible outcomes were assigned based on our judgment.

\subsubsection{Scenario description}

In this example, we assume that a fault tree analysis has identified the potential problem of a large leakage from an isolated LPG storage tank and estimated the frequency with which this problem is expected to occur. A further event tree analysis, as shown in Figure 1 yields 10 possible scenarios comprised of six distinct outcomes. The six outcomes and their associated frequencies are summarized in Table 1. 
Table 1 Data for the LPG leak problem

\begin{tabular}{l|ccc}
\hline Incident & $\begin{array}{c}\text { Damage } \\
\text { Index }\end{array}$ & $\begin{array}{c}\text { Uncertainty } \\
\text { Frequency }\left(10^{-}\right. \\
6 / y r)\end{array}$ \\
\hline BLEVE & -200 & 25 & 2 \\
Flash fire & -150 & 15 & 32.4 \\
Flash Fire and & -275 & 20 & 8.1 \\
Bleve & & & 40.5 \\
UVCE & -425 & 20 & 8 \\
Local Thermal & -30 & 5 & 9 \\
Hazard & & 1 & \\
Safe Dispersal & -3 & &
\end{tabular}

Detailed descriptions of the possible outcomes may be found in (AICHE, 1989), but we briefly outline them here. A boiling liquid expanding vapor explosion (BLEVE) occurs when a pressurized vessel suddenly fails and its contents flash to the atmosphere, producing a pressure wave. If the expanding substance is also flammable, there is the additional danger of a flash fire. An unconfined vapor cloud explosion (UVCE) occurs when a drifting cloud of flammable vapor ignites and explodes, producing a shock wave. Such a cloud may also ignite but not produce an overpressure wave, thus generating a flash fire. A local thermal hazard will occur if the release burns locally, without flashing back into the tank to cause an explosion. Of course, safe dispersal is the most desirable of these undesirable events, but even this outcome has a negative value associated with a shutdown of the facility. (Fang et al., 2004)

The event tree supplies the possible outcomes and frequencies. In order to apply the VaR analysis, we also need values for these outcomes. We have done this using a damage index that we created, somewhat arbitrarily, for this example. 


\subsubsection{Point system for event damage}

We perform our valuation based on the following damage index scale:

0-10 points: minor damage to the local built environment; rare minor injuries

10-20 points: significant damage to the local built environment; common minor injuries; rare major injuries

20-30 points: severe damage to the local built environment; significant damage to the surrounding built environment; common minor and major injuries; at least one fatality is likely

30-40 points: severe damage to the local and surrounding built environment; significant damage to the natural environment; many minor and major injuries; several fatalities

40-50 points: catastrophic damage to the local and surrounding built environment; permanent damage to the natural environment; many minor and major injuries; dozens of fatalities (Fang et al., 2004)

Based on this scale and our judgment of the damage potentials of the various outcomes, we have assigned damage points to the outcomes, as shown in Table 2. We have also assigned an "uncertainty" to the damage points, which will be used and described later (sections 3.1.4-3.1.6); generally, the uncertainties represent underlying stochastic processes specific to the events but beyond the desired level of model detail. 
Table 2. Revised data for the LPG leak problem

\begin{tabular}{c|ccc}
\hline Incident & $\begin{array}{c}\text { Damage } \\
\text { Index }\end{array}$ & Uncertainty & $\begin{array}{c}\text { Frequency }\left(10^{-}\right. \\
6 / y r)\end{array}$ \\
\hline BLEVE & -200 & 25 & 2 \\
Flash fire & -150 & 15 & 32.4 \\
Flash Fire and & -275 & 20 & 8.1 \\
Bleve & & 20 & 40.5 \\
UVCE & -425 & 5 & 8 \\
Local Thermal & -30 & & 9 \\
Hazard & -3 & 1 & \\
Safe Dispersal & & & \\
\hline
\end{tabular}

Note that we will report the negative of the point value when referring to the damage index, so that negative numbers with higher absolute values indicate worse damage.

\subsubsection{VaR for the case of no uncertainty in event damage}

If there is no uncertainty in the damage associated with any outcome, then the VaR curve is actually a discrete frequency mass function as opposed to a continuous frequency density function. This function is shown in the simple bar graph of Fig. 2 . Each event contributes to the $\mathrm{VaR}$ at exactly one value of the damage index, with a frequency determined by the event tree. We do not show the bar for the outcome of zero damage, which has a frequency of $0.9999 \mathrm{yr}^{-1}$ (assuming that our other outcomes cover all other possibilities), because it would be well off the scale of the chart. The cumulative frequency mass function is shown in Fig. 3. (Fang et al., 2004) 


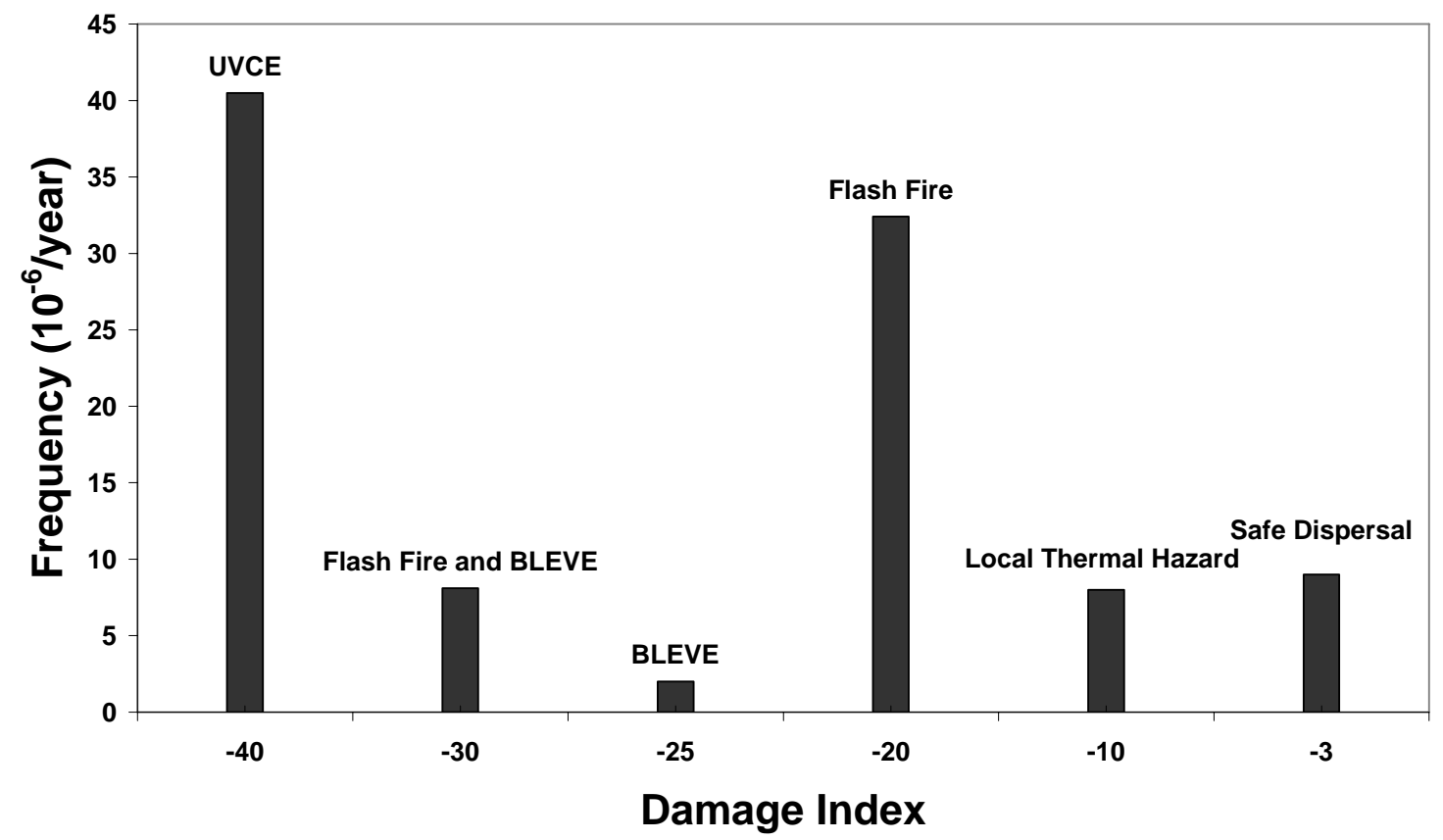

Figure 2. Damage outcome frequencies for the LPG leak (no uncertainty) 


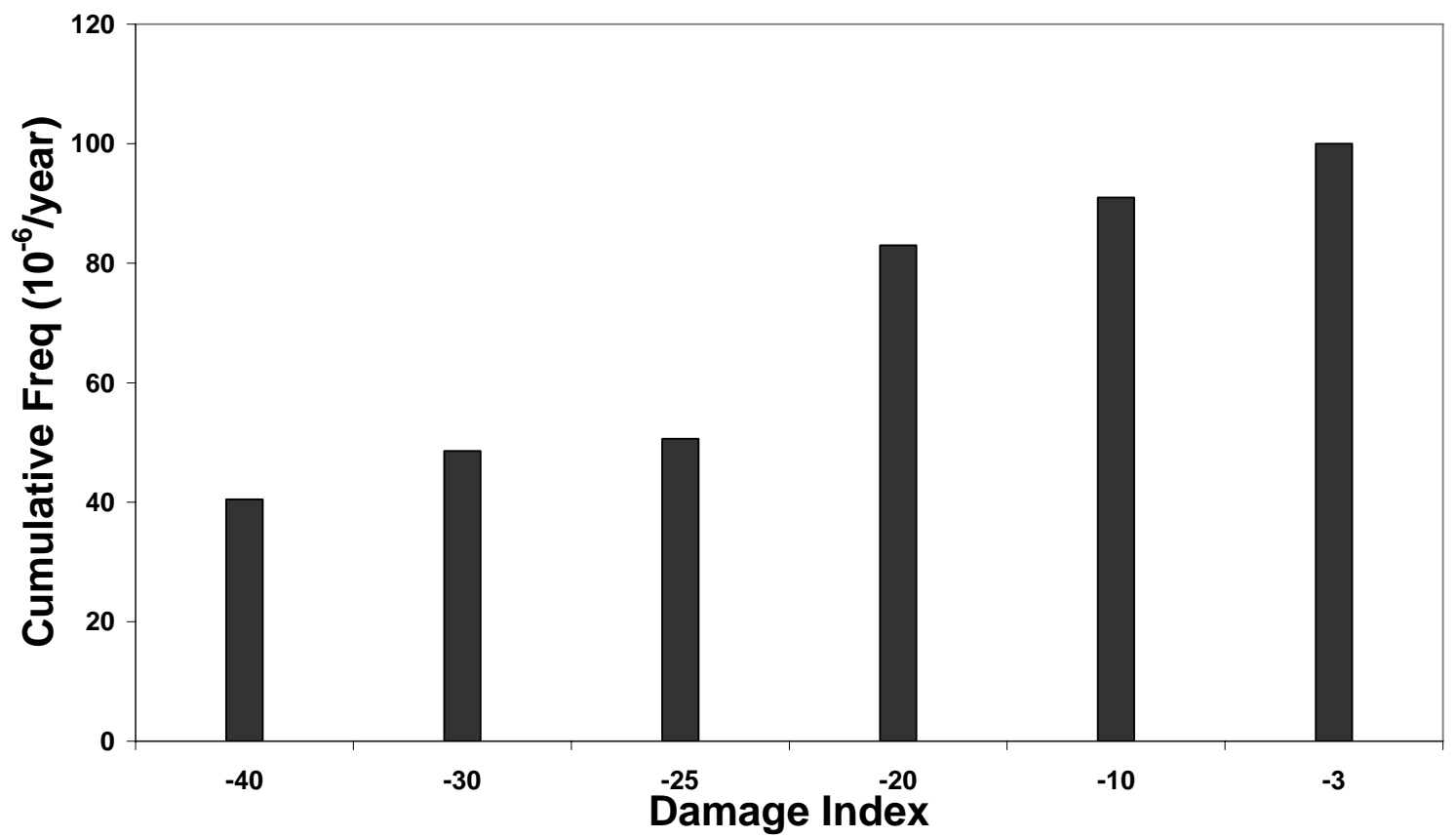

Figure 3. Cumulative mass function for the LPG leak (no uncertainty)

In the financial world, the actual "value at risk" is defined as the value that sets some probability limit on the $\mathrm{VaR}$ frequency function. For example, say that the value $v$ represents a lower limit where 95\% of the frequency lies above it. Then we can state that we are $95 \%$ certain that we will lose no more than $v$ over the time horizon used to construct the frequency curve, or equivalently, "the value at risk is $v$. " Based on the data in Fig. 3, we may make statements such as the following: (Fang et al., 2004)

- We are $99.99 \%$ certain that we will suffer no damage from an LPG storage tank leak over the next year. 
- We are $99.995 \%$ certain that we will suffer a damage value of no more than 30 points from an LPG storage tank leak over the next year.

- Over a one-year time horizon, to a $99.995 \%$ probability level, our value at risk from an LPG storage tank leak is 30 points.

The last two statements are equivalent.

The main assumptions used to generate Figs. 2 and 3 are that (1) the fault tree prediction of $10^{-4}$ LPG storage tank failures per year is accurate, (2) the event tree captures all possible failure outcomes and their associated probabilities, and (3) a single number is sufficient to capture the damage effects of each outcome. The next few sections address the relaxation of the third assumption.

\subsubsection{VaR for the case of uniform uncertainty in event damage}

In reality, many failure outcomes will result in a distribution of possible damage effects, due to stochastic variables such as atmospheric conditions or human factors. To capture the random nature of these processes, damage effects are often modeled as probabilistic functions instead of single values. (Fang et al., 2004)

The simplest approach is to assume a uniform distribution of frequency across some damage range, for each outcome. We demonstrate this approach using the numbers given in Table 1 for the LPG storage tank scenario. The uncertainties of the damage events in the table are used as upper and lower bounds on the distributions, with the frequency being constant between them and zero elsewhere, and the total frequency (area under the curve) being equal to the frequency given in the Table 1. For example, 
the damage index associated with the "safe dispersal” outcome ranges from 2 to 4, with a uniform frequency density of $4.5^{*} 10^{-6}$ events per year per damage point, yielding a total (integrated) frequency of $9.0^{*} 10^{-6}$ events per year. Figure 4 shows the resulting VaR curve. With the use of frequency distributions to describe the damage effects, the curve becomes a frequency density function, instead of a frequency mass function. The curves for different individual outcomes now overlap in certain regions of damage index value and are combined additively in those regions. This additivity is justified because the event tree produces the outcomes as a set of complementary events, in a probabilistic sense. (Fang et al., 2004)

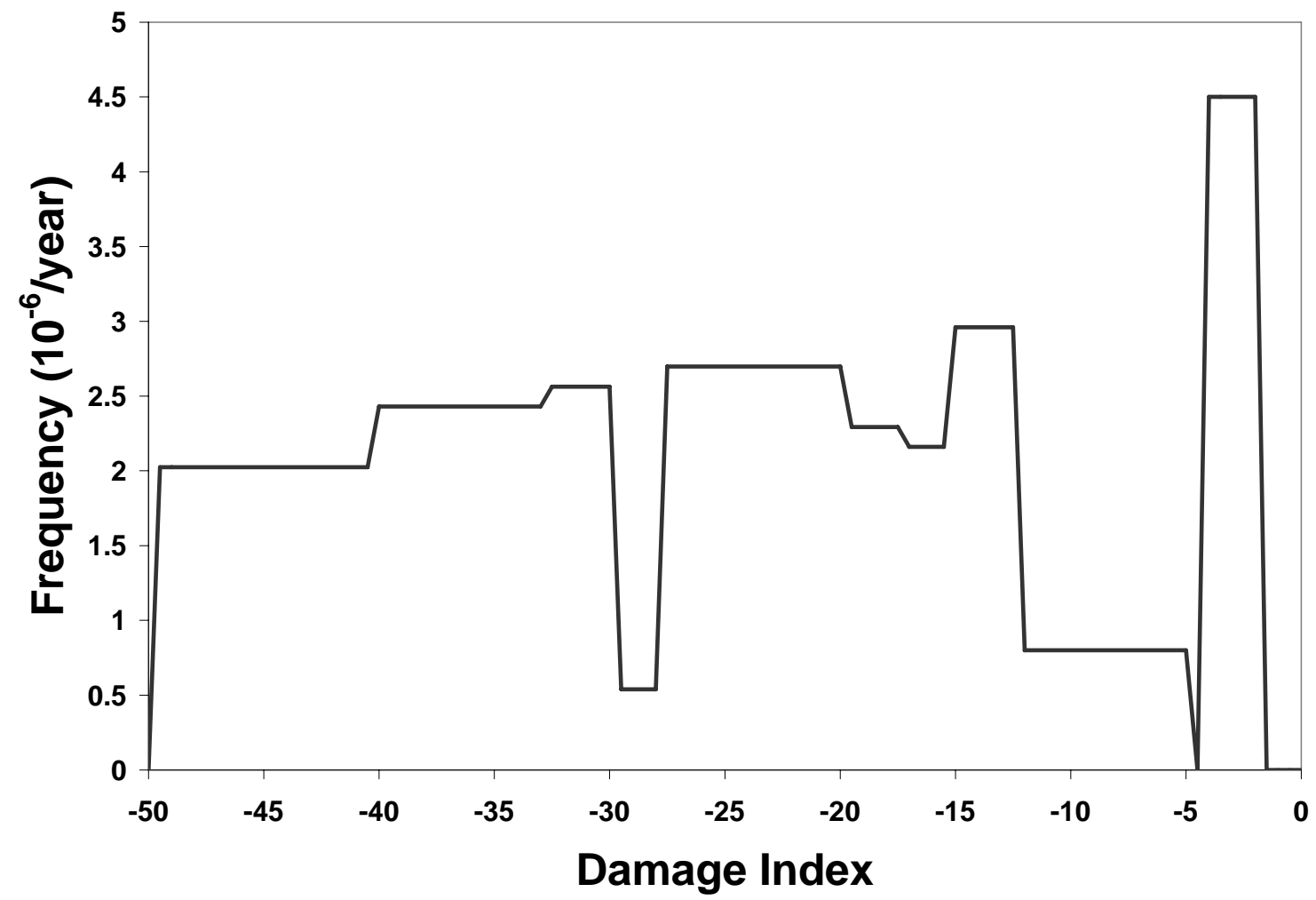

Figure 4. Frequency density function for the LPG leak (uniform uncertainty) 
The corresponding cumulative curve is shown in Fig. 5. The effects of the sharp discontinuities in frequency that exist at the edges of the uniform distributions are evident in the discontinuities of the slope at several locations in Fig. 5.

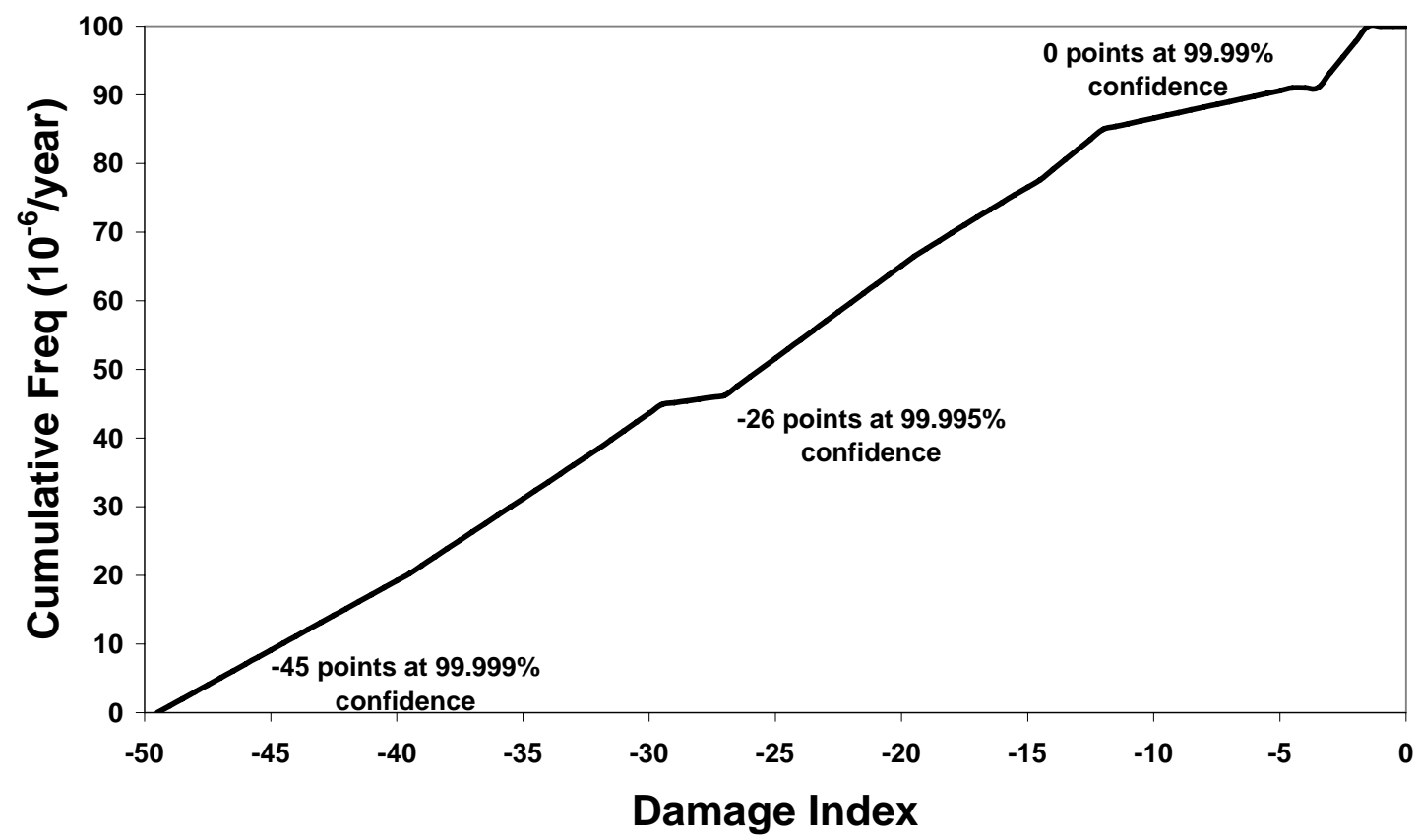

Figure 5. Cumulative distribution function for the LPG leak (uniform uncertainty) 


\subsubsection{VaR for the case of Gaussian uncertainty in event damage}

In this case, we assume that the damage effects are distributed normally. The uncertainties listed in Table 1 are now assumed to be the standard deviations in the Gaussian distributions. For clarity, the entire point scale for damage (section 3.1.2) has been increased by a factor of 10 with new damage scores for each event. These new scores are reflected in Table 2. As with the uniform distributions, each Gaussian is normalized so that the total area under the curve equals the frequency given in Table 2 . The frequency density function is shown in Fig. 6 and the corresponding cumulative function is shown in Fig. 7. (Fang et al., 2004)

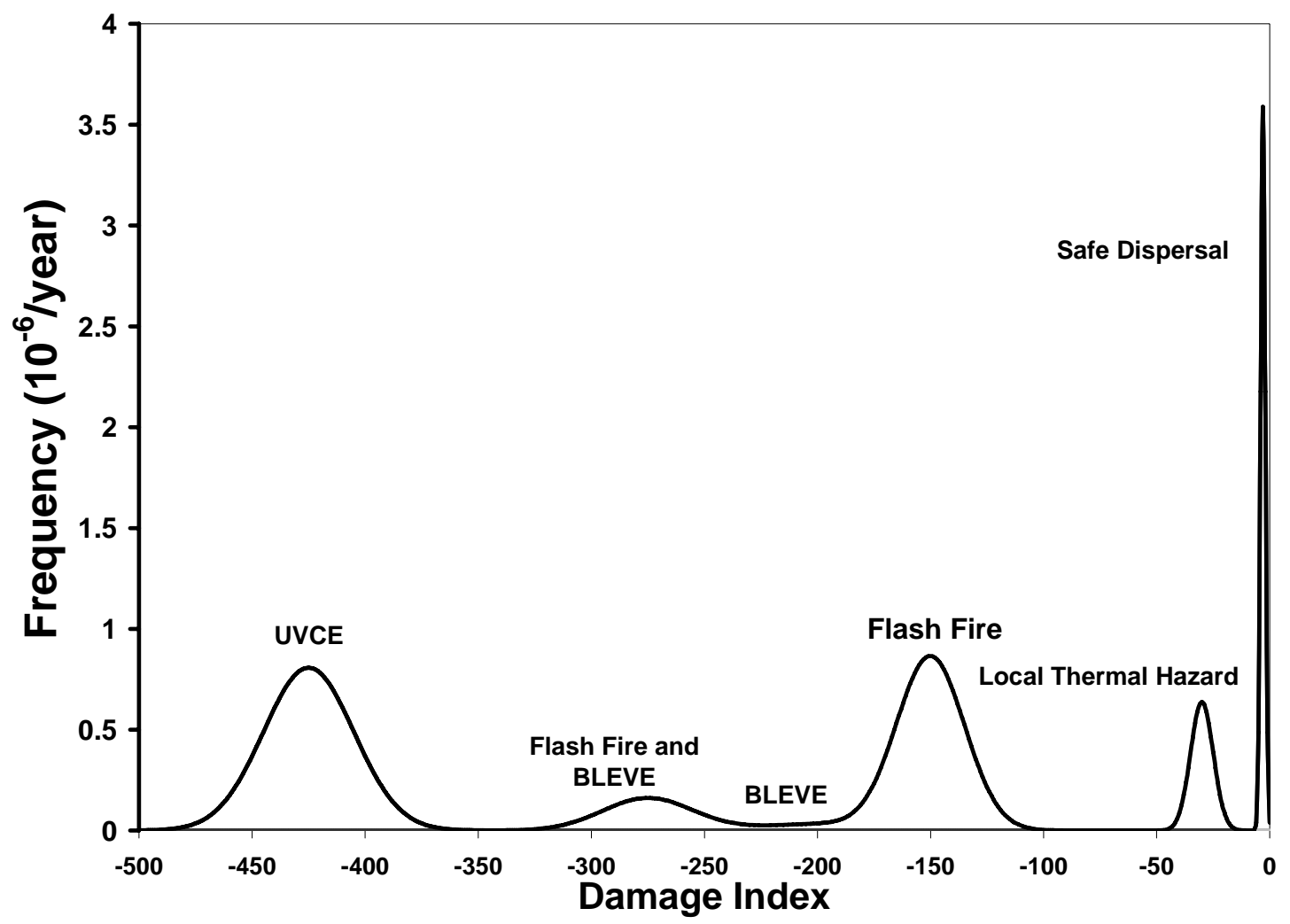

Figure 6. Outcome density function for the LGP leak (Gaussian uncertainty) 


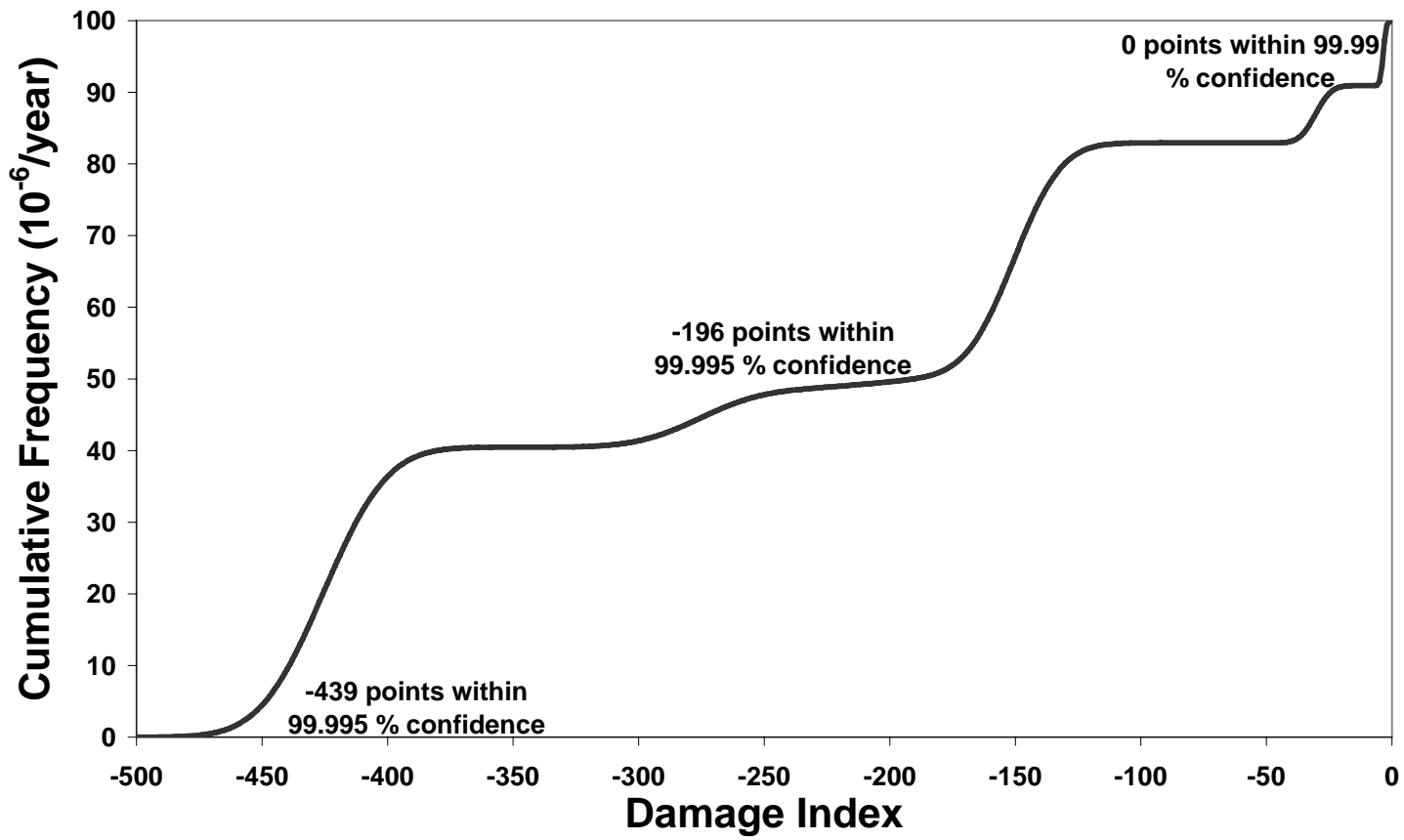

Figure 7. Cumulative distribution function for the LPG leak (Gaussian uncertainty)

With the Gaussian curves, both frequency functions are now smoother. One problem with the normal distribution is that it has infinite range, which may have two undesirable side effects in the present analysis. First, all damage events make some contribution (albeit small) to the positive side of the value curve, which is not sensible. Furthermore, even minor damage events make some contribution (albeit small) to extreme damage values, which is also not sensible. (Fang et al., 2004)

\subsubsection{VaR for the case of beta uncertainty in event damage}

An obvious fix to the problem mentioned above is to use a frequency function with limited range. For this purpose, we employed the beta distribution, which has both lower and upper bounds. The parameters $\alpha$ and $\beta$ for the beta distribution were chosen to match the averages and standard deviations (uncertainties) given in Table 1. 
The density function is shown in Fig. 8, while the cumulative function is shown in Fig. 9. In theory, this is probably the best representation of the results, in that the individual damage events are bounded appropriately. In practice, it doesn’t appear to be much different from the Gaussian results, on this scale. (Fang et al., 2004)

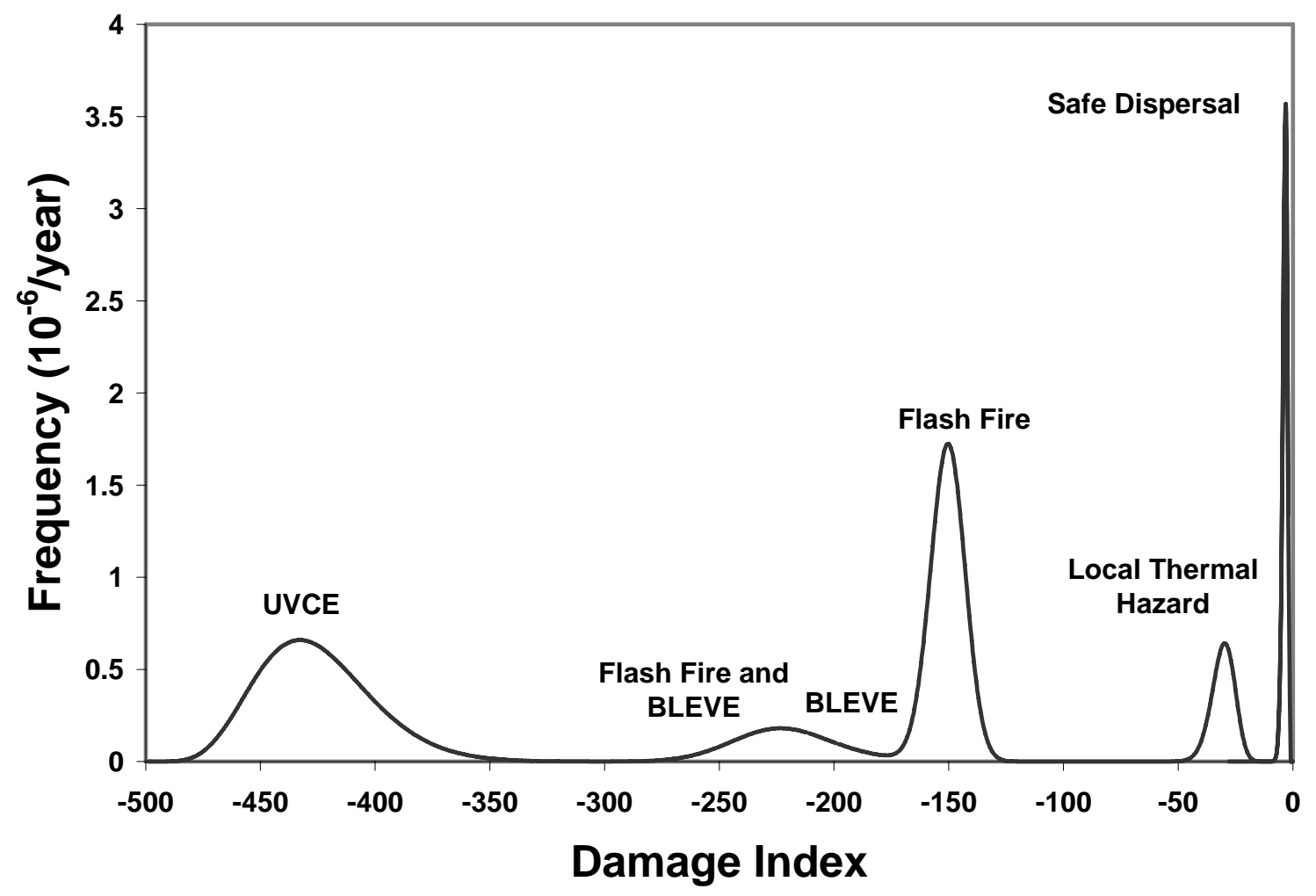

Figure 8. Frequency density function for the LPG leak (beta uncertainty) 


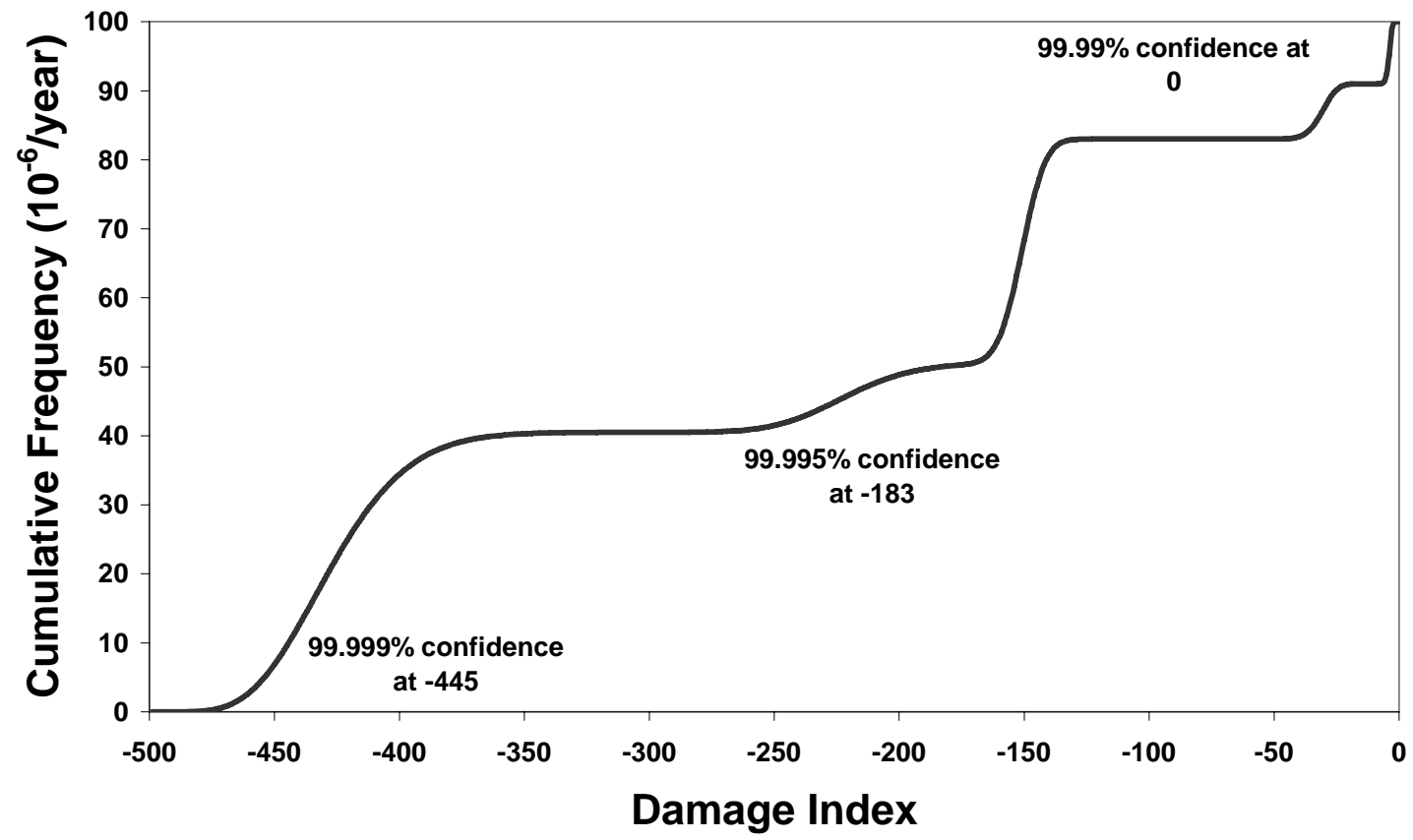

Figure 9. Cumulative distribution function for the LPG leak (beta uncertainty)

\subsection{Second Example Problem: Loading of Chlorine Rail Tank Car}

This example problem applies VaR analysis to a problem illustrated in Chapter VIII of CPQRA. The representative outcomes and their frequencies are taken directly from that reference. The damage index used for this example was created by Khan and Abbasi (1997a).

\subsubsection{Scenario description}

In this example, we assume that an incident identification analysis has generated a set of representative events associated with a chlorine tank car loading facility, and we further assume that a combination of historical data and fault tree analysis has been used 
to estimate their frequency. The three representative outcomes and their associated frequencies are summarized in Table 3. Another parameter that affects the consequences of the incidents is prevailing wind conditions. We will assume eight possible wind directions that are given an equal frequency of occurring. (Fang et al, 2004)

Table 3. Data for the chlorine rail car problem

\begin{tabular}{l|ccc}
\hline Chlorine Potential & \multicolumn{3}{|c}{ Gas } \\
Accidents & Estimated frequency $\left(\mathrm{yr}^{-1}\right)$ & release $(\mathrm{kg} / \mathrm{s})$ & Gas release in one hour \\
\hline Liquid Leak & $5.80 \mathrm{E}-04$ & 2.7 & 1620 \\
Vapor Leak & $6.60 \mathrm{E}-04$ & 0.26 & 156 \\
Relief valve discharge & $3.00 \mathrm{E}-06$ & 2.4 & 8640 \\
\hline
\end{tabular}

Detailed descriptions of the possible incidents may be found in CCPS, but we briefly outline them here. The main elements of the facility are a storage tank, a rail tank car, and associated transfer equipment. A small leak of liquid chlorine ( $2 \mathrm{~kg} / \mathrm{s}$ for $10 \mathrm{~min}$ ) might arise from a defective hose or valve, or an impact to a transfer pipe. A small vapor leak ( $0.2 \mathrm{~kg} / \mathrm{s}$ for $20 \mathrm{~min}$ ) might arise from the same sources. A large vapor leak ( $\sim 2 \mathrm{~kg} / \mathrm{s}$ for $60 \mathrm{~min}$ ) might occur due to a lifting of the relief valve under the stress caused by an external fire. In all three cases, the primary concern is the toxic effects of the released chlorine; the loading facility is located $100 \mathrm{~m}$ west of a residential area 400 m square, containing a uniformly distributed population of 400 persons. (AICHE, 1989)

\subsubsection{Point scale for damage events}

We use the Accident Hazard Index (AHI) due to Khan and Abbasi (1997a). While their approach provides a means to rank three types of damage, namely thermal, 
mechanical (blast), and toxic, we will focus on toxic damage for this example problem of chlorine release.

Khan and Abbasi's procedure for determining the contribution to the AHI of a toxic load involves the following steps. First, a parameter $R$ is estimated from

$$
R=\left(\frac{q}{L C_{50}}\right)^{1 / 3}
$$

where $L C_{50}$ is the concentration $\left(\mathrm{kg} / \mathrm{m}^{3}\right)$ of chlorine vapor that is expected to be lethal to $50 \%$ of the exposed population and $q$ is the total quantity $(\mathrm{kg})$ released. The value of $\mathrm{R}$ is used as input to a function that produces a dimensionless severity factor $X$. If the event is completely contained in the process area, this severity factor $X$ is then the AHI. If an external effect (such as harm to population areas) is a concern, a population impact factor must be integrated with the severity factor $X$ to produce the final AHI.

In this example, the direction of the prevailing wind during a release event is an extra stochastic factor. If the wind carries the chlorine vapor into the nearby residential area, an impact factor must be included. We assume that this will happen when the wind blows towards the northeast, east, and southeast (a total of $37.5 \%$ of the time). There are now two possibilities for the AHI associated with each event, one with the population impact factor and one without. The population impact factor is derived from a special formula derived from Khan and Abbasi (1997b); the input parameters are population density, which is the number of people (thousands) per square kilometer. 


\subsubsection{Analysis of scenario}

Since no uncertainty in the hazard index was available, we carried out a simple frequency mass function analysis for the VaR plot, as in Section 3.1.3.

The frequency mass distribution function featuring the three unwanted events (with and without the population damage input) is shown in Fig. 10. The relief valve discharge had the highest hazard index, followed by the vapor and liquid leaks. The vapor indices had the greatest frequency. However, the wind did not affect the vapor leak’s AHI, because the rate of gas release $(\sim 0.2 \mathrm{~kg} / \mathrm{s})$ was too small to be a hazard to a residential population 100 meters away. The resulting frequency mass function plot is shown below in figure 10. The cumulative mass density plot is shown in Fig. 11.

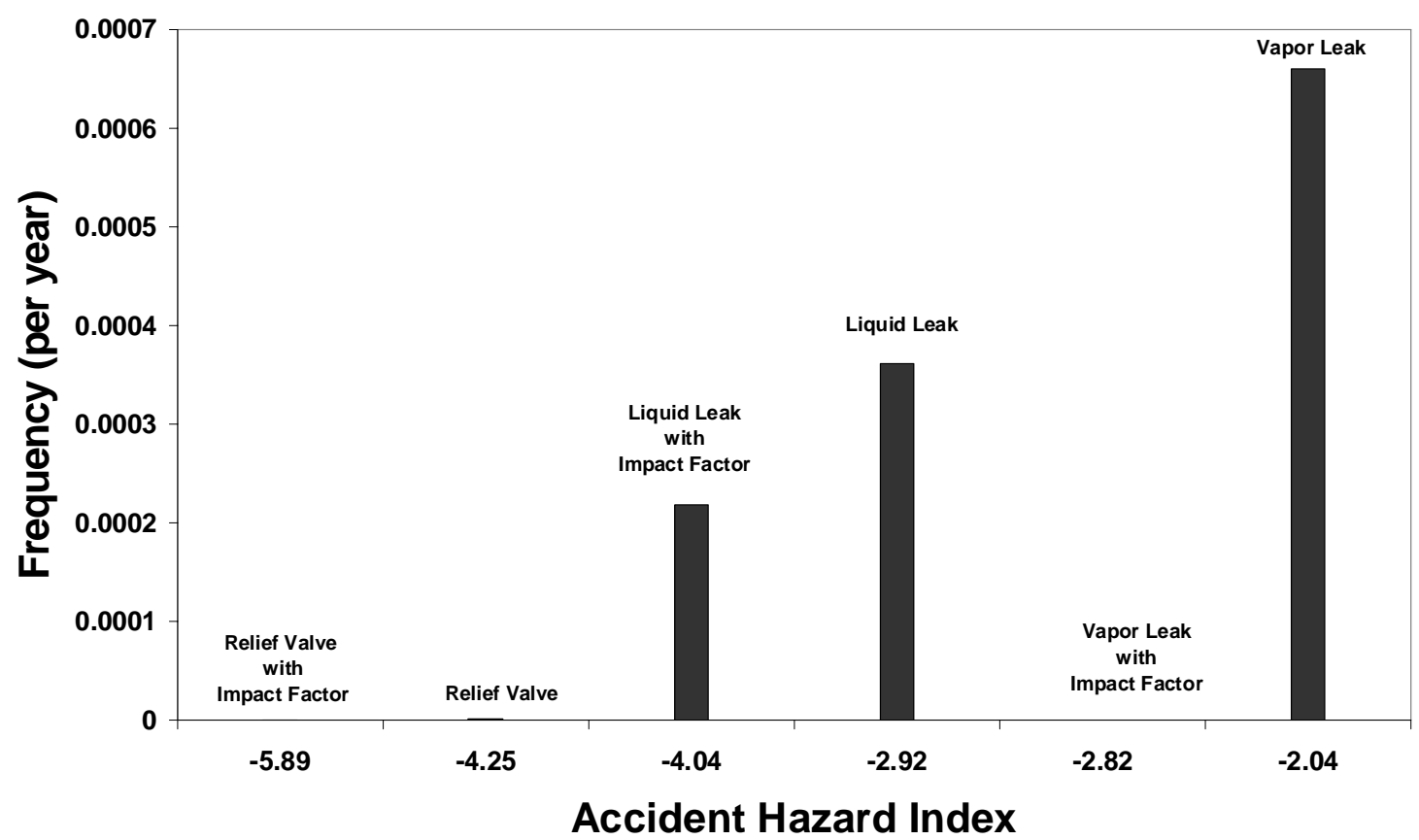

Figure 10. Frequency mass function for the chlorine rail car problem 


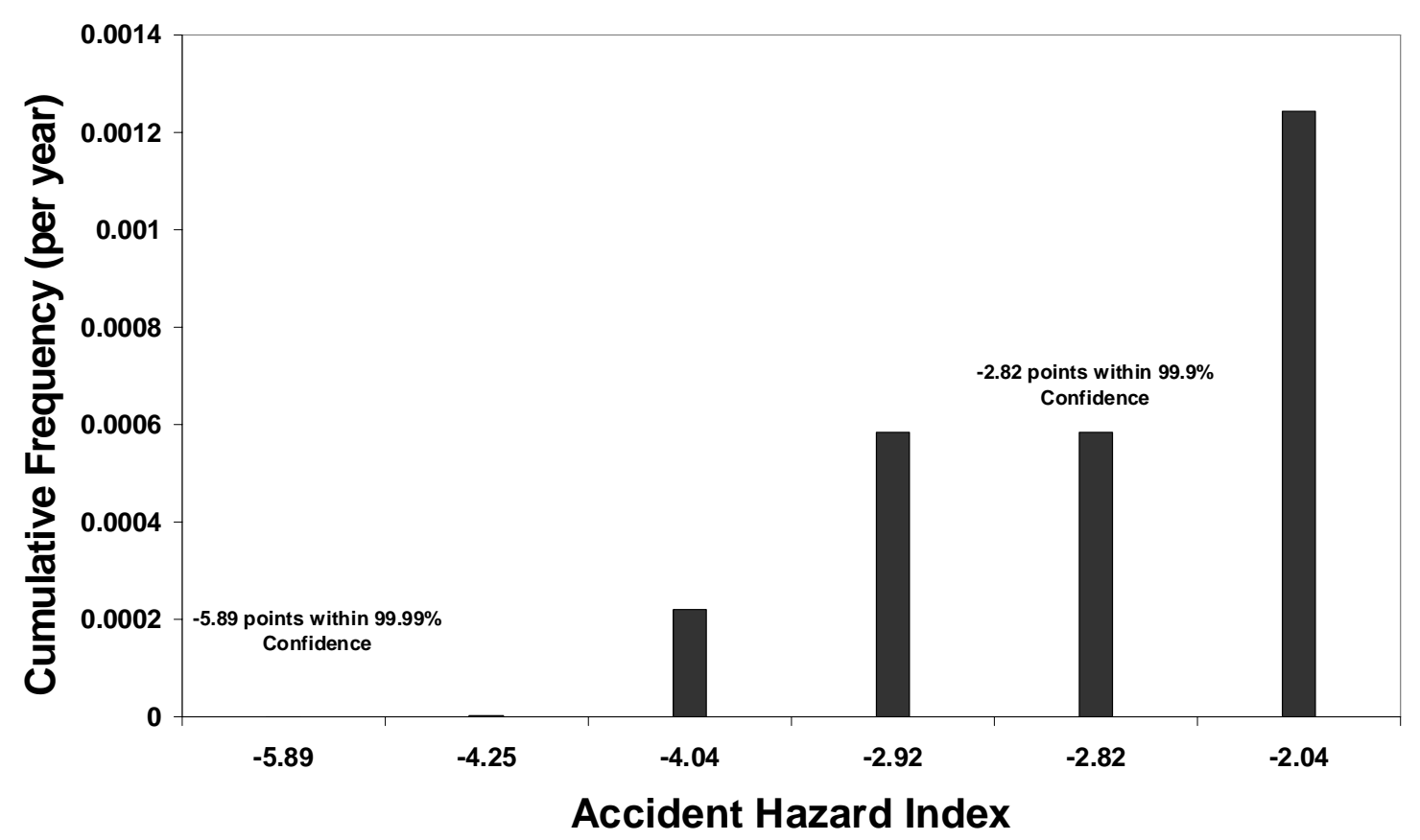

Figure 11. Cumulative distribution function for the chlorine rail car problem

The following VaR statements may be made from the data:

- Over a one-year time horizon, to a 99.9\% probability level, our value at risk from toxic leaks at the tank car facility is 2.82 on the AHI.

- Over a one-year time horizon, to a $99.99 \%$ probability level, our value at risk from toxic leaks at the tank car facility is 5.89 on the AHI. 


\section{CHAPTER IV}

\section{LAYERS OF PROTECTION ANALYSIS EXAMPLE}

\subsection{Introduction}

In the previous section, we demonstrated the application of $\mathrm{VaR}$ to two process safety case studies; event trees for potential incidents with chlorine rail transport and propane gas storage were used to generate $\mathrm{VaR}$ loss probability functions and assess risk. In this chapter we demonstrate the application of $\mathrm{VaR}$ to an ethylene compressor using the Layers of Protection Analysis (LOPA) as it applies to process safety.

\subsubsection{Process description and potential failures}

The main focus of our analysis is an individual ethylene gas refrigeration compressor with a capacity of processing millions of pounds of material per day. Such a device would be found in a liquefied natural gas processing complex, condensing light hydrocarbons for storage and transportation. The compressor, like any piece of equipment, is subject to failures of varying type and severity. We will consider six different types of failure, namely failures associated with surge control, high suction drum level process demand, lube oil control, seal oil control, speed suction control, and vibration process demand. Most of these failure types, if unchecked, would result in approximately one million dollars of equipment damage plus the loss of production from being shut down for about 7 days. The exception is a seal oil control failure, which would incur a 30-day loss of production. To prevent these high levels of damage, one 
may install safety interlocks that shut down, or "trip," the compressor in response to an undesirable event. These shutdowns typically cause the compressor to be down for one business day, significantly limiting the loss. However, one drawback of the interlocks is that they occasionally have spurious trips that shut down the compressor when there is no true process fault; this causes unnecessary loss in production. Details of the interlock implementation are described in the next section.

\subsubsection{Layers of protection}

SIS-Tech (2004) has performed a QRA on a set of safety interlocks for the ethylene refrigeration compressor as described above. The interlocks are layered in series so that if the first interlock does not successfully shut down the system, the second can shut it down, and so on. The QRA is represented as a set of event trees, each modeling the response of the safety system to one of the failure events described in the previous section. Each interlock and event tree is considered to be independent of the others. Figure 12 shows the generic event tree structure. The top event (failure) occurs with an estimated frequency. Each of the safety interlocks provides a success/failure node; there is a certain probability $(x)$ that the interlock will successfully trip the compressor and a complementary probability $(1-x)$ that it will not trip. The upward branch represents a successful trip and ends with a shutdown; the downward branch represents a failure to trip and leads to either a subsequent interlock or ultimate compressor failure (if it is the last layer). The appropriate branch probabilities are multiplied by the top event 
frequency to yield the frequencies of a given sub-event (a successful shutdown or an ultimate compressor failure).

While we consider six types of failure events, there are multiple surge controllers, so there are actually eight distinct top events: (1) $1^{\text {st }}$ SG surge control failure, (2) $2^{\text {nd }} / 3^{\text {rd }} S G$ surge control failure, (3) $4^{\text {th }} / 5^{\text {th }}$ SG surge control failure, (4) high suction drum level process demand failure, (5) lube oil control system failure, (6) LC01 seal oil control failure, (7) speed suction control failure, and (8) vibration process demand failure. Each of the eight top events was given a frequency determined from historical data.

Table 4 provides a summary of the eight top events and their sub-events, corresponding to the response of the safety devices in the different layers of protection. The first column of Table 4 lists the events and sub-events. The second column provides the cost associated with each individual sub-event outcome. The third column provides the frequency associated with each top and sub-event, for the base case of full layers of protection (all devices in place). Subsequent columns represent the same information, but for perturbations of the base case (called "scenarios") where one layer of protection has been removed. The cost data for each sub-event is not scenario-dependent, so it appears in only one column. The frequencies and costs for a top event and its sub-events can be mapped directly onto an event tree like that shown in Fig. 12. 


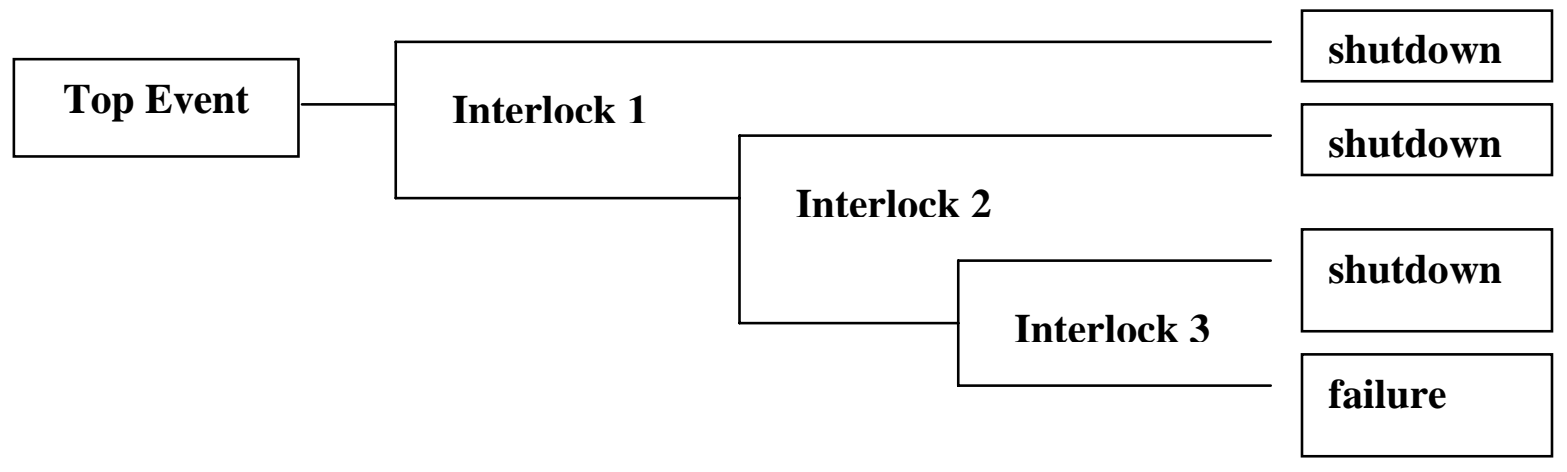

Figure 12: General form of event tree

Spurious trips of these safety devices are summarized at the bottom of Table 4, with the considered possible trips being (1) Overspeed 1, (2) Overspeed 2, (3) Vibration, (4) KO drum level 1-5, (5) lube oil pressure, and (6) SO level. Each of these spurious trips may be considered as an independent, individual sub-event for the purposes of the following discussion. 
Table 4. Frequencies and cost data for all the events and cases

\begin{tabular}{|c|c|c|c|c|c|}
\hline Top Event & $\begin{array}{l}\text { Cost (US } \\
\text { dollars) }\end{array}$ & $\begin{array}{c}\text { Base Case } \\
\text { (1/year) }\end{array}$ & $\begin{array}{c}\text { Scenario } \mathrm{w} / \mathrm{o} \\
\text { overspeed } \\
\text { interlock } 1\end{array}$ & \begin{tabular}{|r|} 
Scenario w/o \\
overspeed \\
interlock 2 \\
\end{tabular} & $\begin{array}{c}\text { Scenario w/o } \\
\text { Vibration } \\
\text { Interlock }\end{array}$ \\
\hline (1) SG surge control fails & & $1.60 \mathrm{E}-01$ & 1.60E-01 & 1.60E-01 & $1.60 \mathrm{E}-01$ \\
\hline Overspeed interlock 1 success & $\$ 270,000$ & $1.57 \mathrm{E}-01$ & $0.00 \mathrm{E}+00$ & $1.57 \mathrm{E}-01$ & $1.57 \mathrm{E}-01$ \\
\hline Overspeed interlock 2 success & $\$ 270,000$ & $3.64 \mathrm{E}-03$ & $1.56 \mathrm{E}-01$ & $0.00 \mathrm{E}+00$ & $3.64 \mathrm{E}-03$ \\
\hline Vibration interlock success & $\$ 270,000$ & $8.47 \mathrm{E}-05$ & $3.64 \mathrm{E}-03$ & $3.61 \mathrm{E}-03$ & $0.00 \mathrm{E}+00$ \\
\hline Vibration interlock failure & $\$ 2,500,000$ & $2.02 \mathrm{E}-06$ & $8.96 \mathrm{E}-05$ & $8.88 \mathrm{E}-05$ & $8.68 \mathrm{E}-05$ \\
\hline (2) $2 n d / 3$ rd SG surge control fails & & $1.36 \mathrm{E}-01$ & $1.36 \mathrm{E}-01$ & $1.36 \mathrm{E}-01$ & $1.36 \mathrm{E}-01$ \\
\hline Overspeed interlock 1 success & $\$ 270,000$ & $1.33 \mathrm{E}-01$ & $0.00 E+00$ & $1.33 \mathrm{E}-01$ & 1.33E-01 \\
\hline Overspeed interlock 2 success & $\$ 270,000$ & $3.09 \mathrm{E}-03$ & $1.33 \mathrm{E}-01$ & $0.00 E+00$ & $3.09 \mathrm{E}-03$ \\
\hline Vibration interlock success & $\$ 270,000$ & $7.20 \mathrm{E}-05$ & $3.10 \mathrm{E}-0.3$ & $3.03 \mathrm{E}-03$ & $0.00 \mathrm{E}+00$ \\
\hline Vibration interlock failure & $\$ 2,500,000$ & $1.71 \mathrm{E}-06$ & $7.36 \mathrm{E}-05$ & $7.20 \mathrm{E}-05$ & $7.23 \mathrm{E}-05$ \\
\hline (3) 4th/5th SG surge control fails & & $1.36 \mathrm{E}-01$ & $1.36 \mathrm{E}-01$ & $1.36 \mathrm{E}-01$ & $1.36 \mathrm{E}-01$ \\
\hline Overspeed interlock 1 success & $\$ 270,000$ & $1.33 \mathrm{E}-01$ & $0.00 \mathrm{E}+00$ & $1.33 \mathrm{E}-01$ & $1.33 \mathrm{E}-01$ \\
\hline Overspeed interlock 2 success & $\$ 270,000$ & 3.09E-03 & $1.33 \mathrm{E}-01$ & $0.00 E+00$ & 3.09E-03 \\
\hline Vibration interlock success & $\$ 270,000$ & $7.20 \mathrm{E}-05$ & 10E-03 & $3.03 \mathrm{E}-03$ & $0.00 \mathrm{E}+00$ \\
\hline Vibration interlock failure & $\$ 2,500,000$ & 1.71E-06 & $7.36 \mathrm{E}-05$ & $7.20 \mathrm{E}-05$ & $7.23 \mathrm{E}-05$ \\
\hline (4) High level process demand & & $1.00 \mathrm{E}-02$ & $1.00 \mathrm{E}-02$ & $1.00 \mathrm{E}-02$ & $1.00 \mathrm{E}-02$ \\
\hline KO Drum LVL Interlock 1-5 & $\$ 270,000$ & $9.77 \mathrm{E}-0.3$ & 9.77E-03 & 9.77E-0.3 & 9.77E-03 \\
\hline Vibration interlock success & $\$ 270,000$ & $2.25 \mathrm{E}-04$ & $2.25 \mathrm{E}-04$ & $2.25 \mathrm{E}-04$ & $0.00 \mathrm{E}+00$ \\
\hline Vibration interlock failure & $\$ 2,500,000$ & $5.35 \mathrm{E}-06$ & $5.35 \mathrm{E}-06$ & $5.35 \mathrm{E}-06$ & $2.30 \mathrm{E}-04$ \\
\hline (5) Lube Oil con & & .01E-01 & $1 \mathrm{E}-01$ & E-01 & $1.01 \mathrm{E}-01$ \\
\hline Lube oil pre & $\$ 270,000$ & $9.87 \mathrm{E}-02$ & $9.87 \mathrm{E}-02$ & $7 \mathrm{E}-02$ & $9.87 \mathrm{E}-02$ \\
\hline Vibration interlock success & $\$ 270,000$ & $2.27 \mathrm{E}-03$ & $2.27 \mathrm{E}-03$ & $2.27 \mathrm{E}-03$ & $0.00 \mathrm{E}+00$ \\
\hline Vibration interlock failure & $\$ 2,500,000$ & $5.41 \mathrm{E}-05$ & $5.41 \mathrm{E}-05$ & $5.41 \mathrm{E}-05$ & $2.32 \mathrm{E}-03$ \\
\hline (6) LC01: & & $0 \mathrm{E}-02$ & $0 \mathrm{E}-02$ & $0 \mathrm{E}-02$ & $9.80 \mathrm{E}-02$ \\
\hline SO level interlock success & $\$ 270,000$ & $9.58 \mathrm{E}-02$ & $9.58 \mathrm{E}-02$ & 9.58E-02 & $9.58 \mathrm{E}-02$ \\
\hline SO level interlock failure & $\$ 7,100,000$ & $2.26 \mathrm{E}-03$ & $2.26 \mathrm{E}-03$ & $2.26 \mathrm{E}-03$ & $2.26 \mathrm{E}-03$ \\
\hline (7) Speed suction control & & $1.30 \mathrm{E}-01$ & $1.30 \mathrm{E}-01$ & $1.30 \mathrm{E}-01$ & $1.30 \mathrm{E}-01$ \\
\hline Overspeed interlock 2 success & $\$ 270,000$ & $1.27 \mathrm{E}-01$ & 1.27E-01 & $0.00 \mathrm{E}+00$ & $1.27 \mathrm{E}-01$ \\
\hline Overspeed interlock 1 success & $\$ 270,000$ & $2.96 \mathrm{E}-0.3$ & $0.00 E+00$ & $1.27 \mathrm{E}-01$ & $2.96 \mathrm{E}-03$ \\
\hline Overspeed interlock 1 failure & $\$ 2,500,000$ & $7.06 \mathrm{E}-05$ & $3.00 \mathrm{E}-03$ & $3.04 \mathrm{E}-03$ & $7.06 \mathrm{E}-05$ \\
\hline (8) Vibration Process Demand & & $1.00 \mathrm{E}-01$ & JE-01 & E-01 & $1.00 \mathrm{E}-01$ \\
\hline Vibration interlock success & $\$ 270,000$ & $9.77 \mathrm{E}-02$ & $77 \mathrm{E}-02$ & 9.77E-02 & $0.00 \mathrm{E}+00$ \\
\hline Vibration interlock failure & $\$ 2,500,000$ & $2.32 \mathrm{E}-03$ & $2.32 \mathrm{E}-03$ & $2.32 \mathrm{E}-03$ & 1.00E-01 \\
\hline \multicolumn{6}{|l|}{ Spurious Events } \\
\hline Overspeed interlock 1 spurious & $\$ 270,000$ & $4.08 \mathrm{E}-02$ & $0.00 \mathrm{E}+00$ & $4.08 \mathrm{E}-02$ & $4.08 \mathrm{E}-02$ \\
\hline Overspeed interlock 2 spurious & $\$ 270,000$ & $4.88 \mathrm{E}-02$ & $4.88 \mathrm{E}-02$ & $0.00 \mathrm{E}+00$ & $4.88 \mathrm{E}-02$ \\
\hline Vibration interlock spurious & $\$ 270,000$ & $7.31 \mathrm{E}-02$ & $7.31 \mathrm{E}-02$ & $7.31 \mathrm{E}-02$ & $0.00 \mathrm{E}+00$ \\
\hline KO DRUM LVL $1-5$ spurious & $\$ 270,000$ & $1.20 \mathrm{E}-02$ & $1.20 \mathrm{E}-02$ & $1.20 \mathrm{E}-02$ & $1.20 \mathrm{E}-02$ \\
\hline Lube Oil press spurious & $\$ 270,000$ & $1.20 \mathrm{E}-02$ & $1.20 \mathrm{E}-02$ & $1.20 \mathrm{E}-02$ & $1.20 \mathrm{E}-02$ \\
\hline SO level spurious & $\$ 270,000$ & $1.20 \mathrm{E}-02$ & $1.20 \mathrm{E}-02$ & $1.20 \mathrm{E}-02$ & $1.20 \mathrm{E}-02$ \\
\hline
\end{tabular}




\subsection{Theory and Methods}

\subsubsection{Calculations of frequencies and cost values}

As mentioned in Section 4.1.2, the sub-event frequencies in Table 4 were obtained from an event tree like that shown in Fig. 12. The frequency of sub-event $i$ is given by

$$
f_{i}=F_{\text {top }} \prod_{j=1}^{i} p_{j}
$$

where $F_{\text {top }}$ is the top event frequency and $p_{j}$ is the appropriate conditional branch probability at node $j$. The $p_{j}$ were obtained from historical performance data.

For clarity, we briefly describe an example of our frequency calculations for the case of SG surge control failure (top event 1) in the scenario without Overspeed interlock 1 (fourth column in Table 4). The top event frequency was assigned a value of $0.16 \mathrm{yr}^{-1}$ based on historical data. Since Overspeed interlock 1 is absent in this scenario, the probability of its success is 0 and therefore the frequency of its success is $\left(0.16 \mathrm{yr}^{-1}\right.$ )$^{*}(0.0)=0.0 \mathrm{yr}^{-1}$. Overspeed interlock 2 is present in this scenario and we assign the probability of its successful response on demand as 0.9769 based on historical data. The frequency for Overspeed interlock 2 success is the product of this probability and the demand frequency under this scenario, i.e. $\left(0.16 \mathrm{yr}^{-1}\right) *(1.0-0.0) *(0.9769)=.0156 \mathrm{yr}^{-1}$. The final layer of protection is the vibration interlock, to which we assign a success probability of 0.9760 on demand. The frequency for successful vibration interlock 
intervention is therefore $\left(0.16 \mathrm{yr}^{-1}\right) *(1.0-0.0) *(1-0.9769) *(0.9760)=0.00364 \mathrm{yr}^{-1}$, and the frequency of failed vibration interlock intervention is $\left(0.16 \mathrm{yr}^{-1}\right)^{*}(1.0-0.0) *(1-$ $0.9769) *(1-0.9760)=0.0000896 \mathrm{yr}^{-1}$. These calculations produce the numerical values found in Table 1. We note that the top event frequency $F_{\text {top }}$ and the probability of success on demand for a given interlock type is held fixed across the different scenarios; it is the presence or absence of a given layer of protection that causes the differences in frequencies observed in Table 4.

Each of the sub-event outcomes has an associated cost. We assume that the cost may comprise both asset damage and business interruption. Business interruption may include both lost (flared) feed and product that was not made. We assume that two hours of feed flaring occurs at every shutdown and that the feed costs $\$ 0.20 /$ pound. We also assume that the earnings before interest, taxes, depreciation, and amortization (EBITDA) is $\$ 0.05$ pound of product. A one-day shutdown from any safety interlock trip will then cost roughly

$$
c_{\text {trip }}=\left(\frac{2}{24} \text { day } \times \frac{4 \mathrm{MM} \mathrm{lb}}{\text { day }} \times \frac{\$ 0.20}{\mathrm{lb}}\right)+\left(1 \text { day } \times \frac{4 \mathrm{MM} \mathrm{lb}}{\text { day }} \times \frac{\$ 0.05}{\mathrm{lb}}\right)=\$ 2,700,000
$$

For most events in which all interlocks fail, there will be approximately $\$ 1 M M$ in damage to the compressor plus a seven day shutdown of the process. The cost will be 


$$
\begin{aligned}
c_{\text {fail }} & =\left(\frac{2}{24} \text { day } \times \frac{4 \mathrm{MM} \mathrm{lb}}{\text { day }} \times \frac{\$ 0.20}{\mathrm{lb}}\right)+\left(7 \text { days } \times \frac{4 \mathrm{MM} \mathrm{lb}}{\text { day }} \times \frac{\$ 0.05}{\mathrm{lb}}\right)+\$ 1,000,000 \\
& =\$ 2,500,000
\end{aligned}
$$

In the special case of the failure of the seal oil control with subsequent failure of all interlocks, the downtime will be 30 days, leading to a cost of

$$
\begin{aligned}
c_{\text {so-fail }} & =\left(\frac{2}{24} \text { day } \times \frac{4 \mathrm{MM} \mathrm{lb}}{\text { day }} \times \frac{\$ 0.20}{\mathrm{lb}}\right)+\left(30 \text { days } \times \frac{4 \mathrm{MM} \mathrm{lb}}{\text { day }} \times \frac{\$ 0.05}{\mathrm{lb}}\right)+\$ 1,000,000 \\
& =\$ 7,100,000
\end{aligned}
$$

So in this particular QRA example there are only three different possible cost outcomes, $c=\$ 270,000, \$ 2,500,000$, or $\$ 7,100,000$. One of these costs is assigned to each sub-event as shown in Table 4, and that cost is independent of scenario.

\subsubsection{Generation of frequency-cost graphs and VaR statistics}

For a given scenario, the total frequency $F_{c}$ at a given cost outcome $c$ was obtained by summing up all of the frequencies as

$$
F_{c}=\sum_{\{\text {sub-events } i\}_{c}} f_{i}
$$


where the sum includes only those sub-events that have the particular cost outcome $c$ (spurious trips included). This was done for each different scenario shown in Table 4 and the results are presented as bar graphs in Section 4.3. These graphs are similar to probability mass function (pmf) graphs in statistics, except that we are plotting frequency (in $\mathrm{yr}^{-1}$ ) instead of normalized probability.

In this chapter we determine $\mathrm{VaR}$ in a more real life method as opposed to the previous theoretical methods in the previous chapters. In financial applications, the actual "value at risk" is defined as the value that sets some lower probability limit on the normalized probability-value function. For example, say that the value $v$ represents a lower limit (typically negative, indicating a loss) where $p_{v}$ of the probability lies above it. Then we can state that we are $\left(p_{v} \times 100\right) \%$ certain that we will lose no more than $v$ over the time horizon used to construct the probability curve, or equivalently, with $\left(p_{v} \mathrm{x}\right.$ 100)\% certainty over the next time period $t$, the VaR is $v$ (Jorion, 2001). A cumulative representation of the probability curve is particularly useful in determining VaR, since one may simply read off the abscissa value $v$ corresponding to the ordinate at the chosen probability level $p_{v}$. In the present case we have only three discrete cost values, so it is more convenient to choose the median cost value and report the corresponding probability level.

As a first step in calculating $\mathrm{VaR}$, we must convert our event frequencies $F_{c}$ to normalized probabilities over a chosen time horizon. Perhaps the simplest approach is to assume that failure events are uncorrelated in time over a given horizon. This assumption is likely to be accurate in our case, because the overarching QRA analysis 
assumes that failures arise from a variety of independent event types and sub-types (as shown in Table 4). So we employ a Poisson distribution of events with a one-year time horizon

Since we have a finite number of distinct events and costs, then the Poisson process assumption implies that the subprocesses dealing with the individual scenarios are independent Poisson processes. Specifically, assume there are k costs associated with frequencies $f_{1}, f_{2} \ldots f_{K}$ normalized to sum to 1 . Then the number of events with cost $c j$ in a time period of length $T$ is a poisson with mean $\mathrm{f}_{\mathrm{c}} T \lambda$ and is an independent set of events with different costs. The chance of at least one event with cost $c_{c}$ in a time period of length is shown in equation 9.

$$
p_{c}=1-e^{f_{c} T \lambda}
$$

where $\mathrm{T}$ is equal to the time horizon, in our case one year, and $\lambda$ is the rate of events in units of $\mathrm{yr}^{-1}$. These probabilities can be used to construct the cumulative mass functions (cmf) and subsequently calculate VaR values, as described above.

\subsubsection{Total expected cost value}

A total expected cost value for each scenario was calculated as

$$
\langle E\rangle=c_{C} f_{C} T \lambda
$$


where the sum runs over all possible cost outcomes $c$ (in our example, there are three outcomes).

\subsection{Results}

\subsubsection{Overview}

Results for the four scenarios shown in Table 1 are presented and discussed in this section. The scenarios are the base case (full layers of protection), overspeed interlock 1 removed, overspeed interlock 2 removed, and the vibrational interlock removed. The different scenarios are presented side-by-side in the figures for convenient comparison. The frequency versus cost graphs are shown in Fig. 13, the cumulative mass function (cmf) graphs (as calculated via the procedure described in section 4.2.2) are shown in Fig. 13a, and the total expected values (section 4.2.3) are shown in Fig. 14a. The (b,c) figures associated with Figs. 13 and 14 are magnifications of the low-frequency, highcost events, which can be difficult to see. The results of all the function studies are summarized in Table 5. 


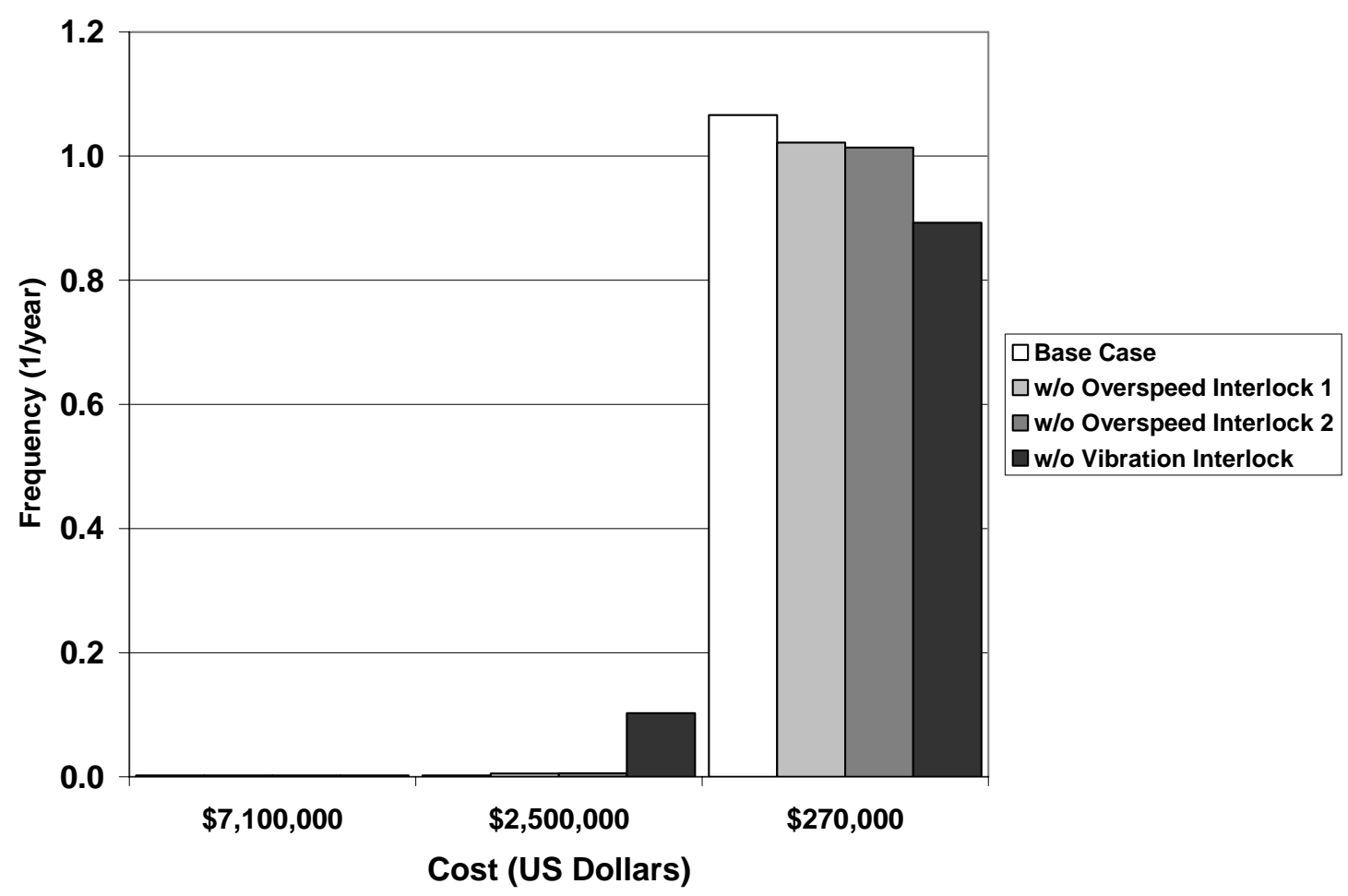

Figure 13a. Outcome frequencies at all cost levels across all scenarios 


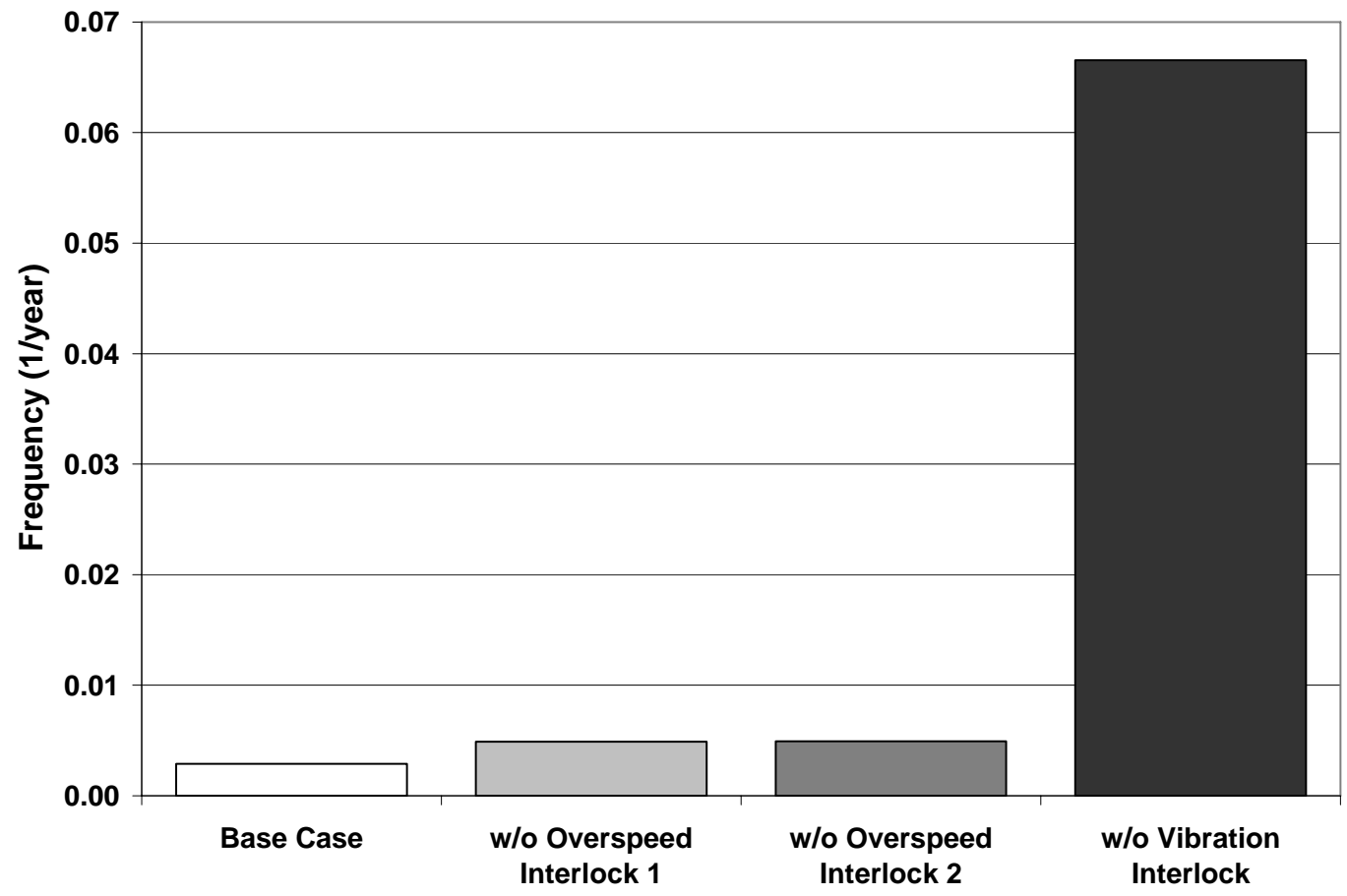

Figure 13b. Close-up view of outcome frequencies at the $\$ 2,500,000$ cost level 


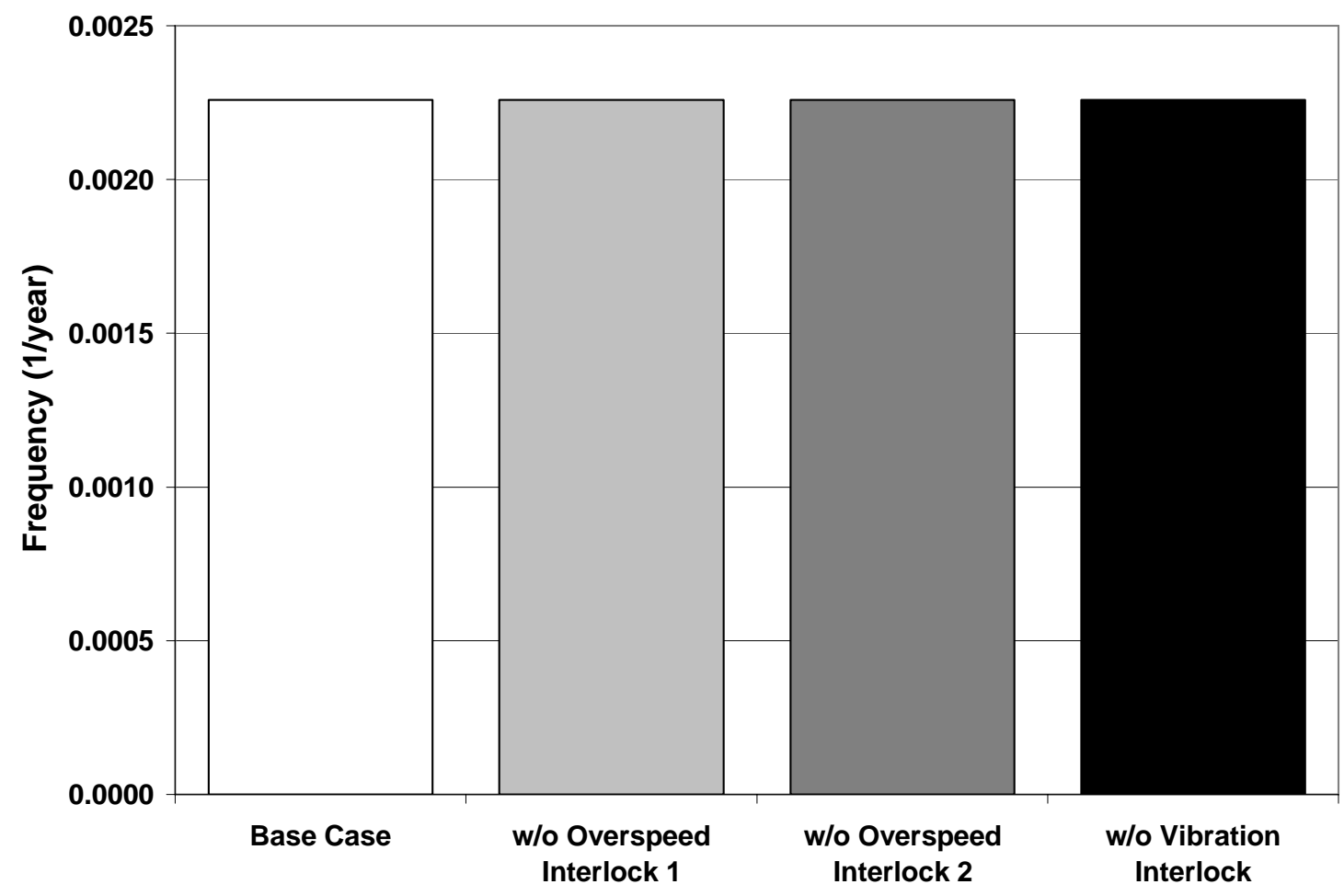

Figure 13c. Close-up view of outcome frequencies at the $\$ 7,100,000$ cost level 


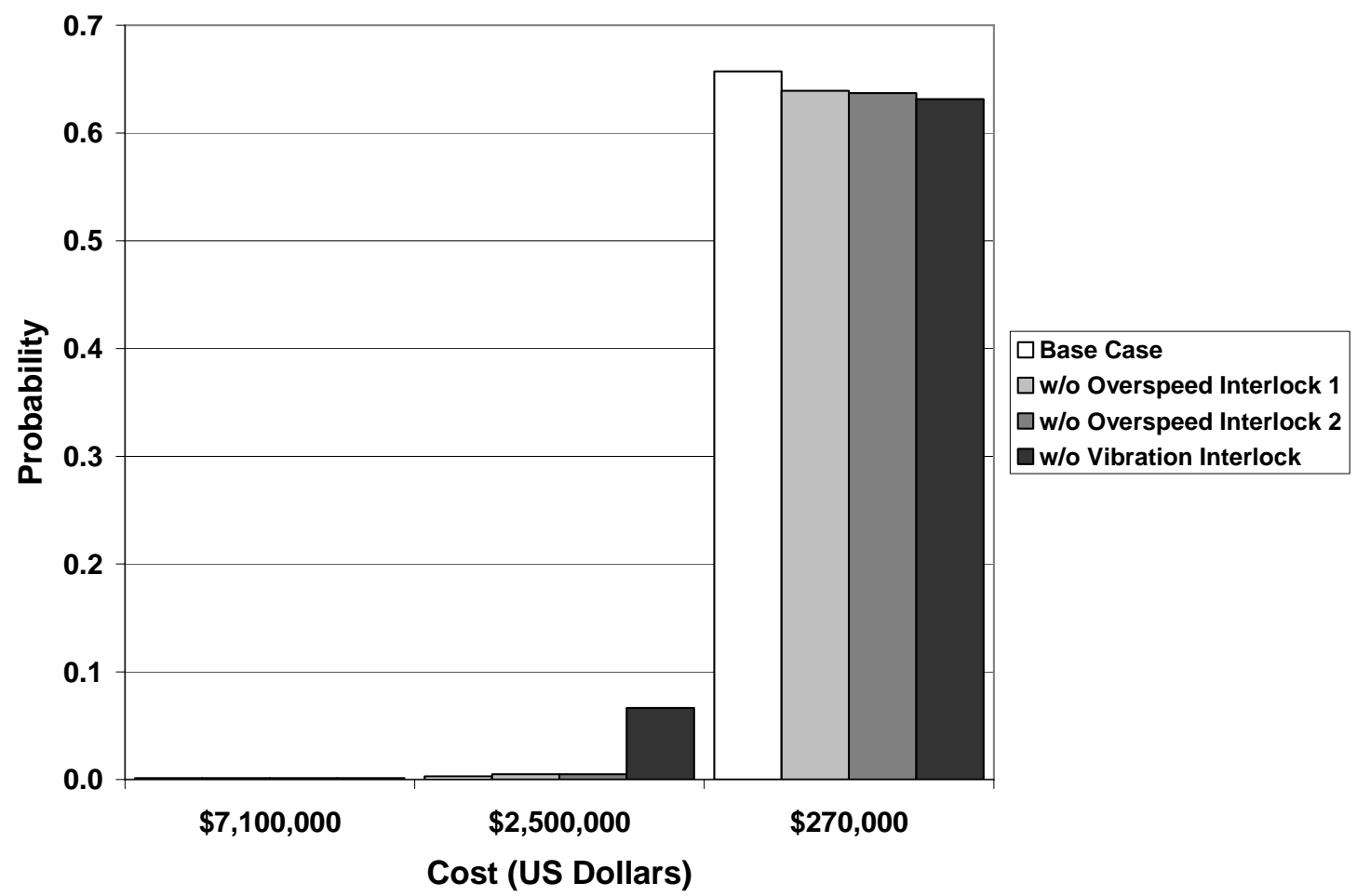

Figure 14a. Cumulative mass probability functions for each scenario 


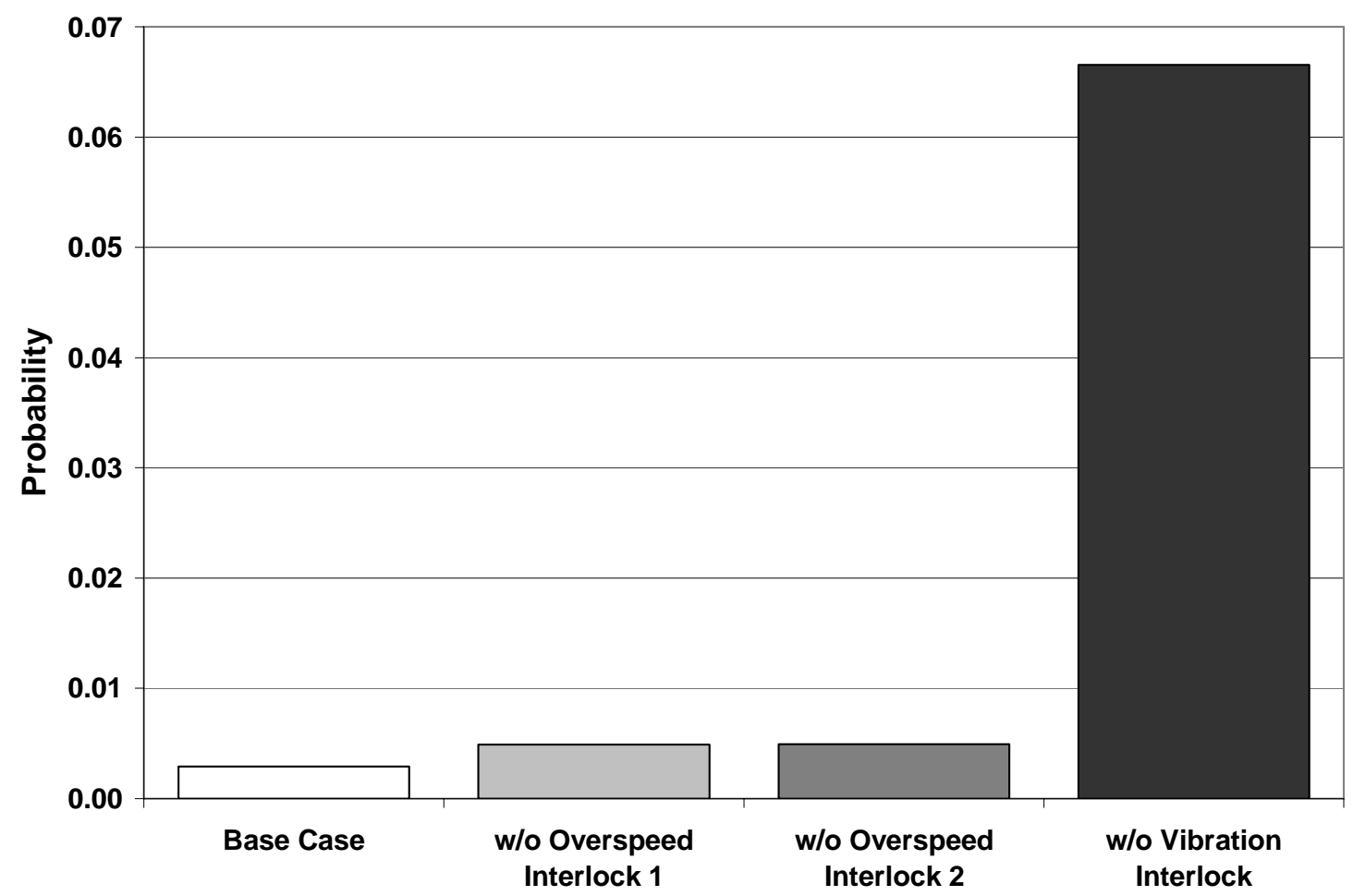

Figure 14b. Close-up view of the cumulative mass functions at the $\$ 2,500,000$ cost level 


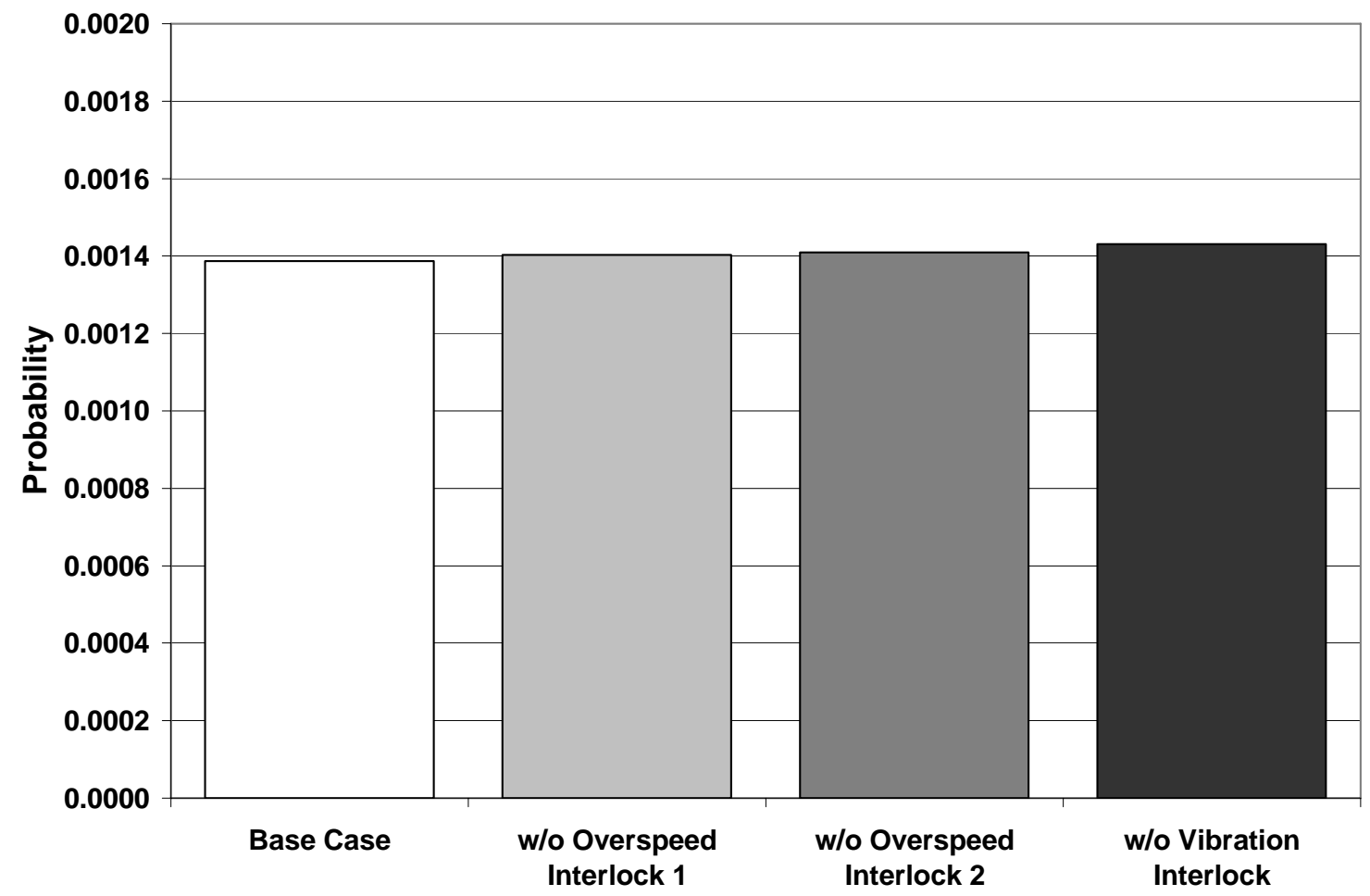

Figure 14c. Close-up view of the cumulative mass functions at the $\$ 7,100,000$ cost level 
Table 5. Frequency and cumulative probability data for all of the scenarios

\begin{tabular}{|c|c|c|c|c|}
\hline Scenario & Base & w/o Overspeed 1 & w/o Overspeed 2 & w/o Vibration \\
\hline Cost Outcome Function & (1/year) & (1/year) & (1/year) & (1/year) \\
\hline$\$ 270,000$ & 1.066 & 1.0218 & 1.0138 & 0.8925 \\
\hline$\$ 2,500,000$ & 0.002455 & 0.005613 & 0.005648 & 0.1029 \\
\hline$\$ 7, \mathbf{1 0 0 , 0 0 0}$ & 0.002259 & 0.002259 & 0.002259 & 0.002259 \\
\hline Cumulative Mass Function & (Probability) & (Probability) & (Probability) & (Probability) \\
\hline$\$ 270,000$ & 0.6540 & 0.6372 & 0.6343 & 0.5500 \\
\hline$\$ 2,500,000$ & $5.631 \mathrm{E}-06$ & $3.060 \mathrm{E}-05$ & $3.122 \mathrm{E}-05$ & $1.055 \mathrm{E}-02$ \\
\hline$\$ 7,100,000$ & $4.766 \mathrm{E}-06$ & $4.956 \mathrm{E}-06$ & $4.995 \mathrm{E}-06$ & $5.115 \mathrm{E}-06$ \\
\hline Total Expected Cost Values & $\$ 283,012$ & $\$ 270,407$ & $\$ 268,256$ & $\$ 212,923$ \\
\hline \multicolumn{5}{|l|}{ Var Confidence Table } \\
\hline$\$ 0$ & 34.60 & 36.28 & 36.57 & 45.00 \\
\hline$\$ 270,000$ & 99.9994369 & 99.996940 & 99.996878 & 98.94510 \\
\hline$\$ 2,500,000$ & 99.9995234 & 99.9995044 & 99.9995005 & 99.9994885 \\
\hline$\$ 7, \mathbf{1 0 0 , 0 0 0}$ & 100.0 & 100.0 & 100.0 & 100.0 \\
\hline
\end{tabular}

\subsubsection{Base case}

The base case represents full layers or protection, meaning the compressor is equipped with Overspeed interlock 1, Overspeed interlock 2, and Vibrational interlock. The base case data in Fig. 13a may be used to make several statements. For example, a catastrophic event costing the company $\$ 7,100,000$ will happen with a frequency of 0.002259 per year (which equates to $\sim 440$ years per loss of this magnitude), and a shutdown at the least costly level of $\$ 266,667$ will happen with a frequency of 1.066 per year. Value-at-risk statements can also be made from the corresponding cumulative probabilities shown in Fig. 14a. For example, over a one-year time horizon, we are 99.9994\% confident that there will be no worse than a $\$ 270,000$ loss. 


\subsubsection{Case without overspeed interlock 1}

In this case, we examine the impact of removing overspeed interlock 1 layer of protection. As shown in Table 4, we removed the benefits of overspeed interlock 1 from all top events and removed the possibility of spurious trips of that device. Removal of this layer of protection affected five of the eight top events.

Figure 14a shows that removing overspeed interlock 1 involves a tradeoff between risk at different cost levels. Removing this interlock reduces the frequency of $\$ 270,000$ cost events to $1.022 \mathrm{yr}^{-1}$, as compared to $1.066 \mathrm{yr}^{-1}$ in the base case. However, for the medium $(\$ 2,500,000)$ cost category the frequency is increased by $0.0031 \mathrm{yr}^{-1}$. With this tradeoff comes less satisfying $\mathrm{VaR}$ values as compared to the base case; there is only a 99.9969\% probability level that the cost will be no worse than $\$ 270,000$. This analysis clearly frames the impact of including, or omitting, Overspeed interlock 1 layer of protection.

\subsubsection{Case without overspeed interlock 2}

In this scenario, we removed a different layer of protection, Overspeed interlock 2 (Overspeed 1 layer remained in place). Using the same procedure as in the previous scenario, we altered the frequencies of sub-events and spurious trips accordingly (see Table 4). The removal of this interlock affected the same 5 out of 8 top events that first scenario did. 
Figures $13 \mathrm{~b}$ and 14b show that the effects of removing overspeed interlock 2 are almost identical to the effects of removing overspeed interlock 1 . The VaR value is $99.9969 \%$ at the $\$ 270,000$ mark. This is perhaps not surprising because the Overspeed interlock 1 and Overspeed interlock 2 always appeared in series under the same top events.

\subsubsection{Case without the vibrational interlock}

In this scenario we removed the vibration interlock, a layer of protection that does not always follow in series with the two aforementioned layers of protection. This particular layer of protection affects six of the eight top events.

Removing the vibrational interlock is much more detrimental to the entire safety

plan. Although there is a significant $0.1735 \mathrm{yr}^{-1}$ decrease in frequency at the low $(\$ 270,000)$ level, there is a two order-of-magnitude increase in frequency in the medium $(\$ 2,500,000)$ level. There is a $98.95 \%$ probability level that the cost will be no greater than $\$ 270,000$, which is a much lower probability than any of the previous cases.

\subsubsection{Total expected value for damage cost}

The total expected loss value for each scenario is shown in Fig. 15; this is a simplified approach where the low probability/high cost - high probability/low cost tradeoffs are not thoroughly examined, but rather all costs are integrated to produce a single expectation value for each scenario. In order of increasing expected cost, the scenario without Vibrational interlock is the least costly followed by overspeed interlock 
2, the scenario without overspeed interlock 1 the base case. As ranked solely by this criterion, the base case scenario is the least costly. The scenario without the vibrational interlock is the most desirable. There is an interesting contrast between this ranking and one based on the VaR criterion, which would show that the base case is the most desirable. This is discussed more fully in the next subsection.

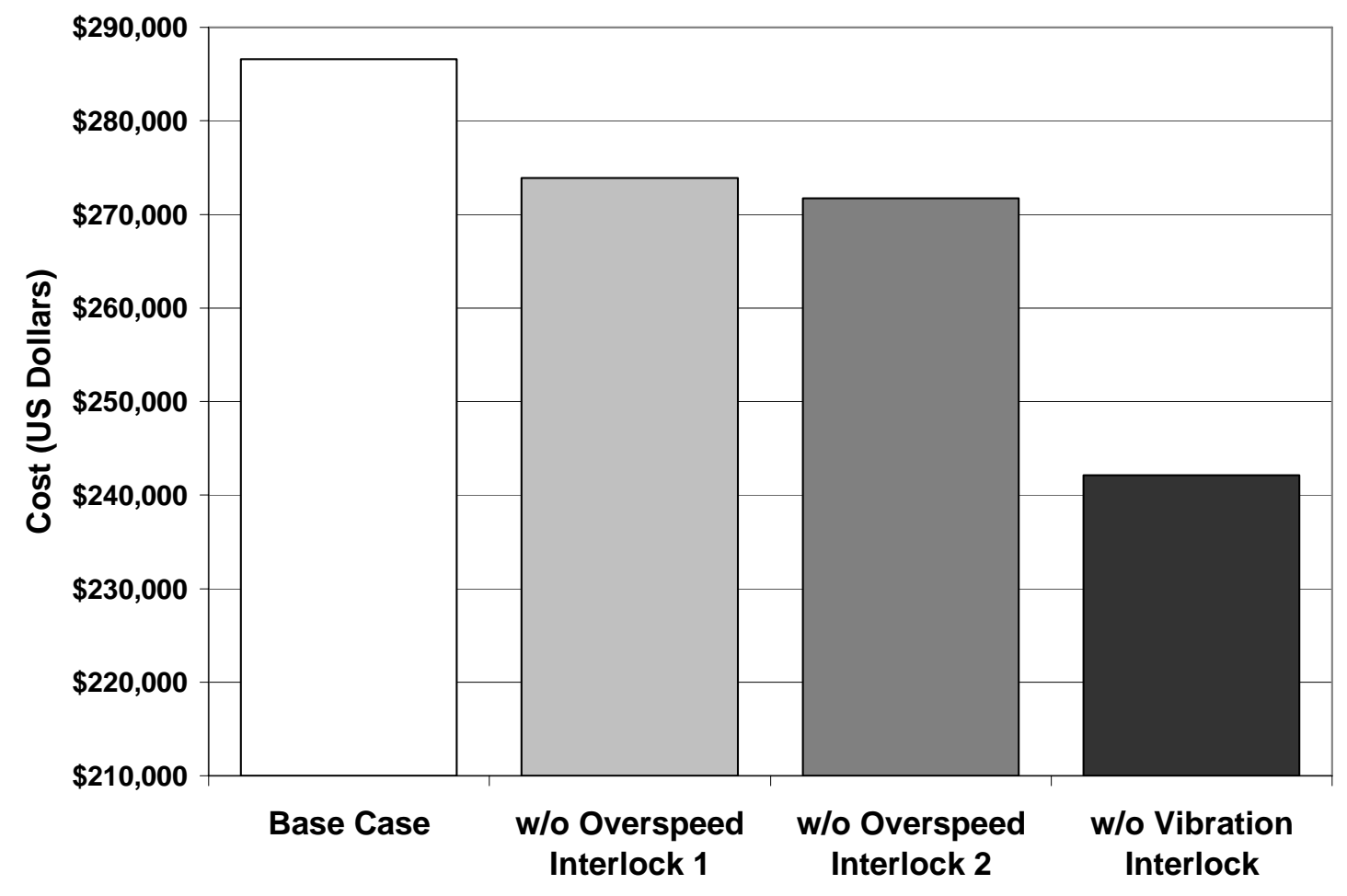

Figure 15. Total expected cost values for the four scenarios

\subsubsection{Best choice among the four scenarios?}

The numerical results of the analysis are summarized in Table 5. The total expected cost analysis and the VaR analysis (CMFs) have contrasting messages. The total 
expected cost favors the scenario without the vibrational interlock over the other three scenarios but the VaR analysis favors the base case over the other three scenarios. The two scenarios without the overspeed interlocks were both medians in both analyses. The total expected cost analysis showed that the vibrational interlock

The difference in conclusions occurs because the VaR probability criterion places more weight on the higher cost levels, while the expected value criterion is based on a straight average. Clearly, one effect of altering the layers of protection scheme is to shift the probability between different cost levels. 


\section{CHAPTER V}

\section{CONCLUSIONS AND FUTURE WORK}

We discussed how VaR concepts from finance might be used to make a better business case for process safety in the CPI. We demonstrated the procedure on two example problems from the CPQRA literature, creating VaR curves based on valuation with different damage/hazard indices (literature-based and customized). The effects of uncertainty in damage associated with possible events were included. In addition, we applied a $\mathrm{VaR}$ analysis to the ethylene refrigeration compressor system safety data provided to us by SIS-Tech (2004). We analyzed the data with all layers of protection included (based case) and in three different scenarios in which one type of interlock was removed. We found that the full layers of protection scheme was conservative, with low frequencies of occurrence for the most costly events but relatively frequent low-cost incidents (spurious trips). Removing the Overspeed 1 and Overspeed 2 interlock lowered the frequency of minor spurious shutdowns but raised the chances, albeit slightly, of a more severe event while the vibrational interlock raised the frequency. The expected value of the costs integrated both the conservative and aggressive schemes. But the VaR tool could give comprehensive approach to which scenario was riskier.

The future work involves using programming software to automate this process of selecting which safety interlocks to use and which safety devices would be worth the cost. Human factors and reliability could also be utilized in this context of valuating process safety. 
Finally, cost benefit and analysis is imperative for decision makers to comprehend the results from risk analysis tools correctly and efficiently and interpret them to informed decisions for the wealth of their enterprise. 


\section{REFERENCES}

Barbaro, A. F., \& Bagajewicz, M. (2006) Managing Financial Risk in Planning Under Uncertainty. AIChE Journal

Center for Chemical Process Safety of the American Institute of Chemical Engineers (AICHE) (1989). Guidelines for Chemical Process Quantitative Risk Analysis. New York: American Institute of Chemical Engineers.

Fang, J.S., Ford, D.F., \& Mannan, M.S. (2004). Making the business case for process safety using value-at-risk concepts. Journal of Hazardous Materials, 115, 17-26.

Jorion, P. (2001). Value at Risk: The New Benchmark for Managing Financial Risk. (2nd ed). New York: McGraw-Hill.

Khan, F.I. \& Abbasi, S.A. (1997a). Hazard identification and ranking: A multi-attribute technique for hazard identification. Report $C P C E / R A$ 22/97, Pondicherry University: Pondicherry, India.

Khan, F.I. \& Abbasi, S.A. (1997b). Accident hazard index: A multi-attribute method for process industry hazard rating. Process Safety and Environmental Protection: Transactions of the Institution of Chemical Engineers Part B 75(4), 217-224.

Pasman, J.(2000). Risk informed resource allocation policy: safety can save costs. Journal of Hazardous Materials, 71, 375-394. 


\section{VITA}

Jayming Sha Fang was born in Morristown, New Jersey in 1978. He graduated with a B.S. from The University of Texas at Austin. After graduating, he worked as a research associate at The University of Texas Materials Science Department working on Fuel Cells.

In January 2003, he enrolled with the Chemical Engineering Department at Texas A\&M University as a Ph.D. student. He received his M.S. in August 2006. 